\title{
The Advent and Evolution of \\ Cybernetics and Political Disengagement
}

\author{
by
}

Caleb Chaplin

A thesis submitted to the Faculty of Graduate and Postdoctoral Affairs in partial fulfillment of the requirements for the degree of

\author{
Master of Arts \\ in \\ Political Science
}

Carleton University

Ottawa, Ontario

\author{
(C) 2011 \\ Caleb Chaplin
}




\section{Library and Archives \\ Canada}

Published Heritage

Branch

395 Wellington Street

Ottawa ON K1A ON4

Canada
Bibliothèque et

Archives Canada

Direction du

Patrimoine de l'édition

395 , rue Wellington

Ottawa ON K1A ON4

Canada
Your file Votre référence

ISBN: 978-0-494-81642-4

Our file Notre référence

ISBN: 978-0-494-81642-4
NOTICE:

The author has granted a nonexclusive license allowing Library and Archives Canada to reproduce, publish, archive, preserve, conserve, communicate to the public by telecommunication or on the Internet, loan, distribute and sell theses worldwide, for commercial or noncommercial purposes, in microform, paper, electronic and/or any other formats.

The author retains copyright ownership and moral rights in this thesis. Neither the thesis nor substantial extracts from it may be printed or otherwise reproduced without the author's permission.
AVIS:

L'auteur a accordé une licence non exclusive permettant à la Bibliothèque et Archives Canada de reproduire, publier, archiver, sauvegarder, conserver, transmettre au public par télécommunication ou par l'Internet, prêter, distribuer et vendre des thèses partout dans le monde, à des fins commerciales ou autres, sur support microforme, papier, électronique et/ou autres formats.

L'auteur conserve la propriété du droit d'auteur et des droits moraux qui protège cette thèse. Ni la thèse ni des extraits substantiels de celle-ci ne doivent être imprimés ou autrement reproduits sans son autorisation.
In compliance with the Canadian Privacy Act some supporting forms may have been removed from this thesis.

While these forms may be included in the document page count, their removal does not represent any loss of content from the thesis.
Conformément à la loi canadienne sur la protection de la vie privée, quelques formulaires secondaires ont été enlevés de cette thèse.

Bien que ces formulaires aient inclus dans la pagination, il n'y aura aucun contenu manquant. 


\section{Abstract}

The consequences of applying principles of "second-order cybernetics" to political organization results in intractable submersion into an artificial, self-referencing framework, wherein the presuppositions of cybernetic epistemology allow for automatic affirmation of every valuation posited within, while simultaneously preventing criticism grounded in a non-technological ontology.

Cybernetic principles of reflexivity, organizational closure, and autopoiesis have since given rise to a post-modern interpretation of cybernetics that is self-referential and mutually reciprocal, wherein observer interactions are incorporated into the system. The cybernetic epistemological framework is internally coherent, situationally adaptive, circular, and given over to systemic incremental refinement. The result is a contained ontological framing conducive for technological innovation but, when applied to social phenomena, allows for arbitrary phenomenal re-valuations.

The primary argument in favour of second-order cybernetics is that it is a logically extensible framework for creating adaptable systems that, in turn, allow for technological innovations that may alleviate man's estate. I argue that this instead constitutes a hermeneutic trap because second-order cybernetic epistemology reifies systemic presuppositions that form the structure of the framework. Traditional political discourse is thereby weakened because it is severed from its connection to the history of philosophical inquiry; this thesis constitutes, in part, a defence of classical political philosophy. 


\section{Acknowledgements}

I am deeply grateful for Dr. Darby's invaluable guidance. Dr. Newell's support was absolutely crucial. I humbly express special gratitude towards Dr. Hutter for

recognizing in me what I had not. And of course, my mother, without whom the possibility of gratitude would not be. 


\section{Table of Contents}

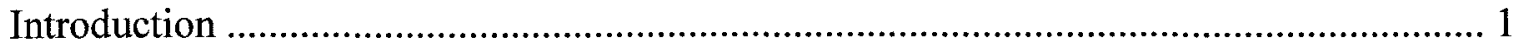

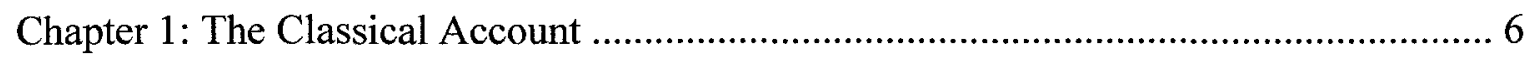

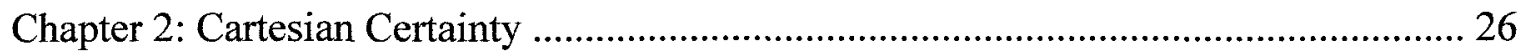

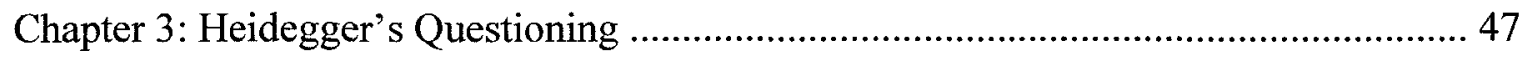

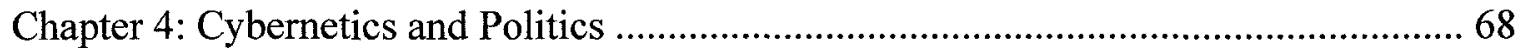

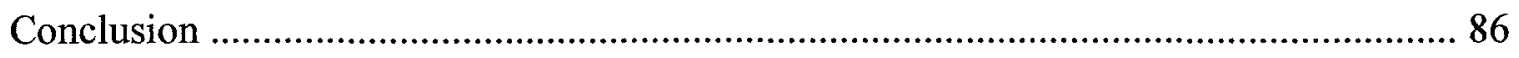

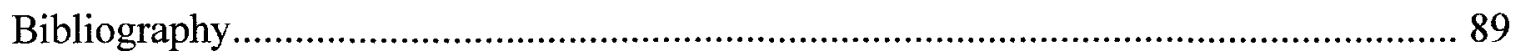




\section{Introduction}

This essay traces the philosophical unfolding that eventually culminates in cybernetics. I begin by examining the origins of techne (Greek: $\tau \varepsilon \dot{\chi} \vee \eta)$ in ancient Greek thought, through to the contributing principles of Enlightenment philosophy articulated by Descartes, Bacon, and Hobbes. Enlightenment thinkers examined metaphysics in light of the emergent new science, a science that established new foundations for examining nature and for developing new ways of examining phenomena. The modern scientific approach to understanding nature culminates with the emergence of cybernetics, which is the field of control and communication theory (Wiener, 1961: 11). Cybernetics is the epitome of technological thinking in Heidegger's critique of technology, a critique I will explore in detail. I also provide a foil to Heidegger's critique by comparing his arguments to theoretical advances made in cybernetics, whereby the principles of cybernetics were applied to its own field resulting in "second-order cybernetics." This broad, theoretical field provided the conceptual grounding for the development of more specifically focused fields, such as robotics, cognition studies, and artificial intelligence. I take the liberty of extending Heidegger's critique to account for these advances by employing Heidegger's writings on ontology and phenomenology, citing his arguments and extending them to address second-order cybernetics.

Heidegger's etymologically grounded analysis of ancient Greek philosophy lays the foundation for his ontological comparison of Cartesian dualism. I will address Heidegger's critique of Descartes in a later chapter but before doing so I will examine the philosophical bedrock from which flourishes the context that allows for Cartesian dualism. In other words, that which allows for a new positioning of man in his relation to 
nature is a relationship that eventually leads to the ever-refining procedures of mastery of nature. Tracing the trajectory of technological thought through modernity requires first examining certain aspects of ancient Greek thought that Heidegger resuscitates in his project. Aristotle's reliance on apophantic statements for discerning truth from falsehood sets the standard for the history of Western philosophy until Nietzsche raises the question of the value of truth. The technological developments of modernity posit that distinguishing between truth and falsehood is of secondary importance to the method that determines the distinction; the emphasis on method is the hallmark of modern scientific thought, a characterization that defines itself over and against Aristotelian Scholasticism.

I will prepare a conceptual backdrop by drawing attention to Roochnik's presentation of pre-Socratic definitions of techne, particularly his assessment of the myth of Prometheus; this will initiate a sustained examination of the unfolding awareness of technique vis a vis man's relation to nature. I draw briefly on Plato's Gorgias to establish an initial difference between knack and techne, and then further examine the varying implementations of techne in the Republic. Afterwards I examine Aristotle's Physics to present his articulation both of a strong aspect of ancient Greek thought regarding man's place in the cosmos and nature, as well as his conceptual model of causal forces. I follow up with the Nicomachean Ethics Book VI, examining the chapters that relate to the different ways of thinking and judging; the section on techne will be dealt with closely.

Broadly speaking, the ancients used the word techne to refer to an activity of crafting and tool-use, typically directed towards the challenge of nature's imposition on human security. These activities emerged in response to observations both of the natural world and human nature. In Aristotle we see a clear link between empirical sense 
observation of nature in the Physics on the one hand, and, on the other hand, the demonstrable characteristic of knowledge articulated in the Ethics. An examination of technology thus requires an examination of the relationships between techne and

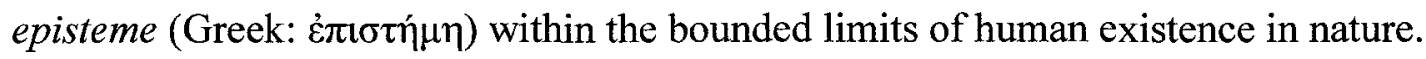

Techne usually carries a positive connotation in ancient writings, for example, Aristotle's writings on home economy (Greek: owאovó $\mu 1 \alpha$ ) suggest that techne properly applied may have a salutary affect on members within the home. This positive connotation becomes ambiguous with the advent of modernity because of the large-scale transformative affect of industry upon nature; though medical advances accrue so too does military development.

The refinement of procedure described by techne is an activity that takes place within the bounds of nature. I agree with Aristotle that techne is a natural thinking activity and I argue further it is an activity that occurs within natural limits - limits that were evident to ancient Greek thinkers and to whom crossing such a boundary would have been at once conceivable and yet also reprehensible. Thus, anterior to an understanding of techne is an ontological stance that generates a unique epistemological framework. I will examine this framework then examine how the shifting stance towards nature in turn alters the epistemological framework following the emergence of Enlightenment science. Heidegger will argue that this framework acquires a reified status with the emergence of cybernetics, a reification that lays the groundwork for a technological-scientific flourishing across an array of fields.

Herbert Wiener names the field of cybernetics from a passage in the Republic, wherein the "true pilot" or "governor" identified by Plato is the individual most capable 
of correctly ascertaining environmental conditions and responding to them in the most

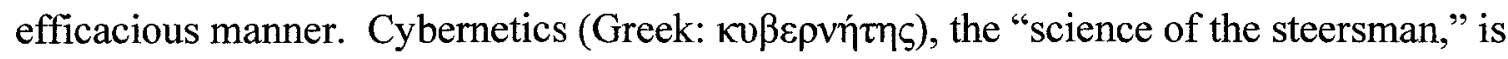
the theoretical formalization of that pilot who is best able to use his knowledge in a manner that draws upon feedback presented by environmental circumstances; the steersman "governs" by readjusting his course according to information gleaned from the environment (Wiener, 1961, 12).

This conceptual framework has been refined over the decades since Wiener first published his book, Cybernetics, and the resulting developments have given way to specialized sub-fields such as robotics, artificial intelligence, missile technology, etc. Military applications remain the starkest consequence but beneficial medical advances have also emerged. These advances are not limited to computer-assisted technology but can conceivably be applied to a host of other fields as well. The application to politics is obvious and suggests the possibility of ever-more precise polling results, voting systems facilitated through online communications, more direct interaction between constituents and elected representatives, etc. Technical means for countering violent oscillations in society to establish increased security and stability is a tempting political goal that cybernetic technologies may offer.

The failure of communist socialism, represented as a competing technological society of the twentieth century next to liberal democracy, is an obvious manifestation of unimpeded and limitless application of technological methods to social organization. Cybernetics is much more subtle and, arguably, much more effective; self-regulation is built into the system and, if properly executed, is theoretically independent of the need for overt manipulation. So long as the configuration is properly engineered then the 
system "runs itself."

At best this might allow for developing the means to ensure stability in elements of the world economy or, on a smaller scale, crime in a city. However, the organizational requirements to ensure such results will only conform to the measurement system already in place. Heidegger's critique of Cartesian ontology bears relevance for attempts at employing technological means to organize society. What eventually emerges is a system that is logically circular, organizationally enclosed, and capable of operating independently of the external context. A self-maintaining organization is the silver bullet for management; in a modern society ostensibly governed by managers the impetus for a technological solution to social woes is clear.

Bacon's call for a new approach to the study of the world established a new orientation towards nature and provided a new image for man in his efforts at selfrecognition. Rather than a being made in the image of God, the Enlightenment increasingly sets the stage for creation of a new image of man. Nietzsche will eventually criticize this image in his critique of the end of Western civilization. In the meantime Descartes' formulation of man's place in the world has not lost traction in the world; if anything it has grown increasingly more pronounced through the development and massparticipation in the global communication network. What this means for politics will be explored in the following pages, but a close analysis of the origins of this trajectory must first be explored. 


\section{Chapter 1: The Classical Account}

This chapter will examine early articulations of techne in classical philosophy, beginning with a brief examination of the myth of Prometheus, then on to the use of techne in Plato's Republic, followed by a sustained analysis of Aristotle's writings on physics, nature, and intellectual virtues. The focus on Aristotelian science and philosophy establishes a necessary backdrop to the changes that take place with the emergence of the Enlightenment because modern science and philosophy was an articulation situated in response to the received philosophy of the Aristotelian Scholastics. Enlightenment philosophy lays the groundwork for modern mathematics and metaphysics, a grounding that establishes further philosophical inquiry eventually leading to cybernetics. The principles that operate upon relatively autonomous and selfadjusting systems represent the core of cybernetics but which are based on Cartesian rationalism. Cybernetics, or "the governing science," is named from the image of the ship in Plato's Republic, an early iteration that describes a more efficacious method based on consideration of environmental variables and circumstance.

Man's relationship to nature changes with the advent of modernity, based on a new position of authority concerning the world and how man operates within it. This change has its origins in the earliest roots of Greek mythology, when the god Prometheus steals the secret of fire and bestows it on man. This myth describes the earliest articulation of the mastery of arts, a mastery that eventually morphs into a form of control that seeks to secure man's safety in the world. This transformation can be traced through key texts by

Plato and Aristotle, whereby they define different ways of thinking that distinguish making from acting. 
By way of introducing Plato I examine the difference raised between knack and techne in the Gorgias. The differences help to determine the initial direction of inquiry into later portions of the chapter; those portions demonstrate the emergent changes with the advent of modern science and technology. One of the key differences, relevant to a comparison of techne and technology, concerns the condition of teachability; examining how a knack differs helps to characterize this difference.

Plato's inquiry into justice raises the question whether wisdom can qualify as a techne, in so far as it may constitute a body of knowledge that can be taught. This inquiry is encapsulated within the debates Socrates holds with his interlocutors in Book I of the Republic concerning different definitions of justice that are raised. This inquiry is crucial for later analysis concerning the political significance of the "city in speech" built by the participants in the conversation.

As indicated, the bulk of Chapter 1 examines Aristotle's philosophy. His clarification of intellectual activity, definitions of physics, as well as his inquiry into human affairs, are primary threads in an ongoing examination that leads to Bacon's reworking of the purpose of science. I draw on themes from the Physics, Ethics, and Politics to present a coherent context for ancient philosophy that will convey the principle elements, and epistemological consequences, that differentiation from modern technology, discussed in Chapter 2. Close examination of his writing reveals distinct characteristics that not only provide points of comparison but also points of departure that characterize the modern scientific project. Nietzsche's writing on the will to power and how this relates to mastery over nature will provide both a capstone on the history of technology but also an introduction into Heidegger's critique of technology in Chapter 3. 
The Greek god most associated with techne is Prometheus. Aeschylus' play, Prometheus Bound, describes the theft of fire from Zeus and the gifting of it to man. The play hints at an aggressiveness towards nature that Bacon will elaborate further, abandoning the passive acceptance of limits imposed by nature. Instead, Prometheus describes a trickery that is suggestive both of the political implications of stealing from the chief of the Olympian gods, as well as the implications of bestowing knowledge of this trickery to man.

Roochnik describes the play as an unselfconscious philosophical work that inquires what extent there is a techne of arête (Roochnik, 40). The characteristics of Promethean techne affects almost all human activity related to culture, and yet is without any clear indication as to the limits of techne itself. As an act of divine endowment, the play suggests that if there are limits to what techne may be applied to then divine sources rather than mortal ones will establish such limits.

Man may be the guarantor of his own limits, from whom there is little incentive to limit technical application. Voegelin argues that Prometheus is said to have a spiritual affliction; while chained to the rock, Hermes declares that Prometheus is afflicted with nosos, suggesting a loss of harmony with the cosmos (Voegelin, 2007: 27). Voegelin identifies in modern technology a Prometheanism that reflects a willful destining within man. This sense of willfulness is a hubristic adoption of a mantle of responsibility regarding man's place in the cosmos; this willfulness is symptomatic of an existential illness whereby man, like Prometheus, mistakenly believes that he possesses the means and wherewithal to assume mastery of nature. In other words, the steersman is writ large 
whereby man transforms the signs seen in nature into information that is then acted upon. For Voegelin, the story of Prometheus illustrates a mistaken conclusion that the eternal order is world-immanent or that it can somehow be used as a governing force.

Hadot explicates a recurring notion within the history of philosophical and scientific thought that nature somehow hides secrets, a notion he traces from Heraclitus through to Goethe. His explication of the emergence of this idea among the ancients culminates in a distinction between a Promethean stance towards nature and, in his words, an "Orphean" stance (Hadot, 2006: 98). The former follows the description I've already provided, in that it entails an aggressiveness towards nature recognizing that mastery of techne can alleviate challenges to human comfort. The Orphean stance is more passive, in that it recognizes foremost the necessity of living within the boundaries dictated by nature. Both stances are oriented towards recognition of the limits of human activity within nature but, whereas the Promethean stance actively promotes mastery of techne, the Orphean stance rather encourages acquiescence and not attempting to push beyond natural limits. They are two sides of the same coin, at once complementing each other while sometimes overlapping at different times in history (Hadot, 2006: 155).

According to Hadot, the Promethean stance is most clearly differentiated from Orphic in the manner by which its activities constitute a form of violence towards nature. Foremost is the practice of experimentation, articulated best by Hippocratic medical practice and Bacon's well-known exhortation to "vex nature for her secrets." Second is the development of mechanics as a technique for tricking nature; the etymological root is $m \bar{e} k h a n \bar{e}$, or trickery, whereby simple tools extrapolated from nature are used in the service of man. Examples include the pulley, wedge, and lever, among others. The third 
form is magic, which constitutes a technique of constraint exerted over invisible powers, such as gods and spirits (Hadot, 92-93).

Prometheus is at once a founder of experimental science who symbolizes the right of dominion over nature, but also a dominion whose moral grounding is based on the desire to help mankind (Hadot, 2006: 98). This humanitarian aspect is mirrored in Bacon's reformulation of man's place in nature but whereas the ancient approach to Prometheanism is limited by boundaries established by nature, the Baconian version is unlimited by nature and explicitly encourages an approach that progressively operates beyond determined limits; this too is humanitarian in essence but requires a set of assumptions concerning human nature that will be elaborated in the next chapter.

Before examining techne in the Republic, I indicate an important distinction in the Gorgias that is raised between techne and knack. Plato makes a distinction between knack and techne in the context of a discussion of knowledge, specifically with regard to the appearance of knowledge. The issue of genuine knowledge is crucial for understanding the distinction between wisdom and rhetoric. Plato's develops numerous metaphors to demonstrate this distinction, such as his images of the cave (515c1), the image of the beast (493b1), and the image of the ship (488b).

In the Gorgias, Socrates asserts that a knack is not a craft because a knack cannot provide an account of the nature of the activity in question (465a). A knack describes a natural facility for or towards some activity. On the other hand, craft describes a coherent method towards the elaboration of a given purpose, in that it may give an account of the activity. Whereas craft is a way of engaging towards purpose already 
forethought, knack is instead a quality that facilitates ends, qualities that may be naturally present or acquired through practice. Knack is imitative in nature, like craft, but not in a procedural manner; rather, it is self-imitative of its own activities. A knack may be cultivated by practice and constitutes an imitative activity principally for itself, rather than the ends towards which a knack facilitates. Whereas knack is imitative of itself, craft is imitative of methods. Craft is the outward manifestation of a method that directly leads to its ends, a definition that I will examine closer with Aristotle's treatment of techne.

The significance of this section relates to Plato's image of the ship in the Republic. The dissimulation of the appearance of knowledge is mirrored in the actions and attitude of the sailors in the image of the ship. In each of the images previously mentioned, Plato illustrates the undue influence of techne on rhetoric in politics; in the case of Thrasymachus and Gorgias, each rhetorician collapses the distinction between the knowledge of his subject matter with their antecedent causes of their respective body of knowledge. That is, they each fail to demonstrate that their knowledge constitutes a coherent body of teachable knowledge, rather than indicate a knack for articulating what their audience wants to hear or might be responsive to.

The first instance of techne in the Republic occurs in the conversation Socrates has with Polemarchus concerning art and the nature of justice (332c5). Reasoning by analogy, Socrates asks what is fitting to the art of medicine (drugs), what is fitting to the art of cooking (seasoning), and what is fitting to the art of justice (Polemarchus' friendenemy distinction). However, because techne always represents a teachable model of knowledge, Polemarchus' definition of justice fails to fulfill the requirements of a techne. 
His definition can be taught, for example, in so far as knowledge of one's allies and enemies can be transmitted to another, but this is not sufficient to constitute a model of knowledge because the model is not consistent; in other words, Socrates refutes Polemarchus by demonstrating that one can be mistaken about whom they consider a friend, which disallows this definition of justice to constitute a techne.

Plato introduces the image of the ship as a response to Adeimantus' objection to the philosophical way of life, a life that would appear to render its practitioners useless to the city $(487 \mathrm{~d} 3)$. The argument creates a tension between the public recognition of political life with the reflective consideration of the philosophical life. The ship analogy demonstrates a relationship between knowledge and opinion on one hand, with education and politics on the other.

The image initially describes a scenario that could occur on any ship, though a little later Socrates explicitly asserts that the image refers to public disposition towards philosophers (489a). The ship owner is stronger than those on board though possessed of weak senses, a prudent observation of politics that those who are fit to rule are not necessarily the best to rule. Leaders must depend on others to provide information on the state of affairs, a key theme that I will address later when technological principles of cybernetics are applied to politics. Thus, even if possessing adequate means for ensuring authority, leadership observations are made through a degree of opacity dependent on the quality of their political advisors.

Returning to Plato's image, the means and resources of the ship owner are what set him apart from the sailors, rather than technical capability; in a literal sense this is so because wealthy citizens were expected to fund military expenditures and would 
occasionally command their own ships. In the image, the sailors witness a perceived equality of capability among themselves and the ship-owner, believing they are no less capable of ruling than the ship-owner. The democratic leveling present in the arrangement between the ship owner and sailors in the image suggests a political environment comparable to democratic Athens and connotes a denigrative quality that hints at the political instability inherent specifically to Athens but also to democratic regimes in the broadest sense.

Dissatisfaction arising from a perceived political inequality leads the sailors to quarrel amongst themselves, each claiming they ought to rule despite none having received formal training. The lack of education permits ignorance of one's ability which in turn leads to a false confidence; from their ignorance the sailors will even deny that training in the navigator's art is at all possible, whereby the sailors are prepared to murder each other in defence of their position. The sailors crowd about the ship-owner begging him to grant them responsibility, however, even if one of them should succeed another sailor may yet murder him. There is a pervasive hint of imminent mutiny and anarchy in the description in what is otherwise an unstable political order.

The sailors confuse "true sailing" of the navigator's art (488d) with theft, suggesting a correlation between the architectonic art of the statesman with the political manipulation and rhetoric of the sophist. The sailors in the image don't recognize that wisdom is associated with knowledge of what is best; instead they confuse wisdom with rhetoric, collapsing the difference between navigation and manipulation. The confusion suffused throughout the image is revealed more so through the counterpoint of the "true pilot," one who possesses applicable knowledge of, e.g., astronomy, meteorology, and "everything 
that is proper to the art" $(488 \mathrm{~d} 3)$.

The sailors and the true pilot exhibit actions indicating the presence of techne in the execution of means. The sailors employ rhetoric and drugs to stupefy the ship owner to wrest control from him; the pilot possesses knowledge of piloting for ensuring that the proper destination is reached. The image certainly describes a political reality on the surface but for the examination of techne it also indicates an awareness of method displayed by the pilot, whereas the sailors are unable to understand that the principles of techne can be redeployed in other capacities, even a techne ostensibly concerned with a seemingly unrelated matter.

In another sense, the true pilot is separate from the piloting craft. Others can use his knowledge for establishing the same effect, i.e., to reach an intended destination. This separation of knowledge from the knower acquires paramount importance with Enlightenment rationalism with Descartes' and Bacon's articulation of the methods of modern science.

It should be noted that when Socrates begins his debate about justice with Thrasymachus, techne is first discussed in the context of navigation. A ship's pilot is defined not by whether he assists in sailing the ship, but rather in his command of the knowledge of shipping and of his commanding sailors to carry out his instructions. Cybernetics is the science of governing, similar to the architectonic arts of politics and architecture, both of which constitute second-order forms of knowledge; that is, they each constitute knowledge that commands both other forms of knowledge and the individuals that specialize in them. 
Aristotle appears to be deliberately ambiguous in his opening commentary on each of the major divisions within the Physics. However, this ambiguity establishes an initial framework for deeper inquiry into natural phenomena that he later clarifies. His chapters typically open with general observations, followed by a summary and refutation of competing arguments, from which he continues to establish his own.

His observations describe the way in which natural phenomena unfold. When Aristotle writes of a "natural way," there is an implication of a way of observing that is simultaneously natural in its own essence, and yet is also natural according to human nature; this observational approach culminates in a broad epistemological structure for a rational examination of nature.

Aristotle rejects several models articulated by past and contemporary philosophers concerning the ontological status of nature. Through Book I, chapter 2, he first associates motion with nature then associates number with nature (185a14). In the Republic, Book II, nature is described as static and motionless; Aristotle rejects this account by describing nature as a dynamic multiplicity.

According to Rosen, the epistemological transition between Plato and Aristotle concerning the ontic status of the observable world has traditionally been the division between the theoretical mathematical approach of Plato and the sense-empiria of physics initially articulated by Aristotle (Zinman et al., 1993: 70). Rosen rather identifies the essential difference as one of production and practice, that is, poiesis and praxis.

Whereas Plato's account of the cosmos is expressed through unity Aristotle describes nature as a multiplicity. By describing nature as motion, multiplicity is necessarily 
inferred, even if only in place. Classical ontology posits that unity of the One takes precedent over the Many, a proposition reflected in several of Plato's dialogues, but this is argued against by Aristotle in his argument for the primacy of multiplicity in nature. He establishes an observational approach that introduces discreet differentiation of natural phenomena, differentiation that eventually becomes radicalized in modernity.

Platonic inquiry leads to a distinction between theory and production, such as between observations that lead to the acquisition of shoemaking knowledge, compared to shoemaking itself. As Rosen indicates, Plato only distinguishes between theoretical and practical modes of intelligence, that is, distinguishing between theoria and praxis eventually leads to the differentiation between science and arts. This is why Rosen argues that politics emerges at the crossroads between theory and practice; politics is an art that commands other arts and if production follows from it then this is a secondary phenomenon of political activity (Zinman et al., 1993: 72).

This is not the place to raise the topic of subject-object dualism in nature (see Ch.2), but some preliminary discussion of Aristotle's ontological approach to the observation of nature is appropriate. This approach is ontological in character because Aristotle is proposing a study of nature based on the positionality of observation relative to causality. By positionality I mean the following: observing a change of status in an entity necessarily entails three components relative to the topic, namely, the initial state during which observation was initiated; the following state after which observation concludes; and the topic itself under observation. For example, an uneducated person (i) becoming an educated person (ii) necessarily entails the topic under observation, in this case the person (iii). 
There is a relationship between the form of the topic or entity under observation and the level of analysis with which it is engaged. For Aristotle, the essence of a thing is necessarily bound up with the purpose towards which it is oriented; for example, the essence of an acorn is bound with its eventual growth into a tree. However, the manner in which it is examined is bound to the expectations of the observer; if the acorn is stripped of all phenomenological significance beyond observable facts then its essence cannot be adequately understood.

This leads Aristotle to examine the tension between sources and constants in book VII of the Physics. In particular, there is a tension between a substance "coming-from" it's constituent elements which is distinct from a material that becomes a new form. For example, a statue that emerges from bronze can be said to be a statue coming from bronze, or a lump of bronze becoming a statue. In either case there are two states (shapeless, shaped) acting upon a constant (bronze). However, epistemological certainty does not entail a transformation of the knower, so much as acquiring an awareness of certain relations between phenomena; the knower is not somehow moved into a new state but rather "by becoming-present of something else" (247b4). The seemingly infinite possibilities of knowledge and becoming is instead an array of potentialities working through possibilities.

This leads to a contradiction between the form and material of a thing in terms of being and becoming. This contradiction can be further discerned by examining a comparison between the ontological assessment of being in contradistinction to nature. Whereas being is associated with stasis in the ordered cosmos of Plato, for Aristotle nature and the cosmos express becoming and change. Material properties tend to be 
persistent but the form of things is more prone to change; therefore, for Aristotle, nature and form are linked. Aristotle's argument reveals a dyadic relationship between matter and form, continuing from an assemblage of less order to increasing order.

The emergence of increasing degrees of order reveals an aspect of the properties of natural phenomena that are both incidental and specific, that is, the particular aspects of phenomena are incidental even though nature itself is not. This incidental character of form is generated by two kinds of potentiality, internal and external. Internal potentiality is natural to the thing, inherent in its essence. For example, this can be seen in a vine that grows into more vines; that is, the nature of a vine is to grow into more vines. External potentiality develops its characteristics only after their application to a thing; for example, wood that is organized into a chair demonstrates characteristics of a chair only after the external potentiality of organization is performed. Thus, the nature of a bed is its form. External potentiality is most clearly seen through conventional uses of material, however, natural phenomena acting upon things falls under the same category, such as lightning transforming a tree into ash. Thus, form is nature by convention but matter is nature by nature (194a23).

The incidental character of form and the external potentiality of convention leads to the issue of appearances. Aristotle attributes importance to the appearance of things that the tradition of philosophy has usually denigrated as mere appearances. For instance, the form that a heart takes is of greater importance than the muscle tissue that it is composed of; if the heart stops beating then it becomes less of a heart because it stops doing what hearts do. In The Life of the Mind, Arendt argues that the form of a thing is the necessary outer expression of its essence (Arendt, 1978: 23). Nature is a dynamic outgrowth of 
potentialities, both internal and external, thus for Aristotle nature is constituted by and expressed as movement, thus, nature moves in the direction of a "from-which" towards a "to-which" whose outer form is like the destination that a path arrives at.

The purposeful movement of potentialities towards the outer manifestation of form requires a closer examination of the principle causes that Aristotle identifies as sources of motion in natural phenomena. This is necessary because Heidegger revisits these observations in his essays on technology and to fully appreciate the significance of his arguments I must elaborate Aristotle's ideas through a closer explication of his text.

The first cause, discussed at length already, is the material, or what Aristotle describes as, "that out of which something comes into being, still present in it" (194b26). The coming-into-being described in the movement of nature towards a given form is due to the essence of the material from which it is comprised. The composition of initial base aspects establishes the scope of potentiality available to transformation while also opening up the possibility of transformation as such. The scope determines a finite set of potentialities that in turn allows for the form that may emerge from the material.

The second cause, then, is the form that material can take after one potentiality from a finite set is established. In full, "This is the gathering in speech of the what-it-is-for-it-tobe, or again the kinds of this, and the parts that are in its articulation" (194b29). This gathering in speech connotes the conventional characteristic of the cause. Through convention is expressed the meaning of things that take shape; in other words, wood in the shape of a chair is such according to the convention that shapes them and are identified as such. As I will examine in Chapter 2, Descartes will further elaborate this distinction with his formulation of metaphysical dualism. 
The convention itself is determined according to the cause that imbues form to shapeless material. The third cause, then, "Is that from which the first beginning of change or of rest is, ... or generally the maker of what is made, or whatever makes a changing thing change" (194b30), i.e., the efficient cause. Aristotle's example includes a legislator of laws and a father of children, which suggests that the third cause introduces willing and choice into the spectrum of causes. Following from willing is action that occurs within the public realm, whereby the political is seen to enter into phenomena, natural or otherwise. The third cause allows for choice and decision-making. This suggests that the first two causes may have a more primal connection to nature, whereas the third and fourth causes are more directly observable in human affairs.

The fourth cause, or the end cause is the teleological purpose that things may possess, in other words, "That for the sake of which," is the last of the concrete causes of motion in nature identified by Aristotle (194b34). Thus, purpose emerging from the organization of matter manifests distinctly through the guidance of convention. The causes mirror Aristotle's description of nature as a "to-which," in that phenomena emerge from matter, are given shape by the conventions of a maker, for a purpose whose ends are rational and foreordained.

Aristotle entertains the possibility that fortune might also qualify as a cause; however, this is couched as an exception to the causes discussed previously. He describes it as an incidental cause because it cannot be directly predicted or counted upon to manifest itself causally. Teleological causes are necessarily linked to rational interaction with the world, so fortune is necessarily linked to action (197b2).

The third cause presents the entry point of choice into phenomena, whereby that 
which is conceived and considered with respect to the affectation of will brings to bear awareness of possibility. This awareness opens the way for the fourth cause, awareness of ends and awareness of means towards those ends. Knowledge of means intimates knowledge of ends and the possibilities that stem from such ends. From the presence of choice into the causa efficiens follows purpose in relation to the world; choice of means for engaging with the world introduces the aspect of politics into consideration of means. As ends are necessarily placed within the broader context of the world, so too are they necessarily within a shared world. As such, politics is in the realm of purpose in so far as an ontological account of worldhood is concerned.

Aristotle articulates a clear causal relationship between phenomena, stripped of animistic and divine association. Events in the world occur due to antecedent events, as he states in his argument for a first mover in the Physics, rather than because of willful deities interceding into the world; he dismisses contemporaneous arguments asserting that the world is static or devoid of motion. By interlinking causal events Aristotle asserts a ranking of causality whereby some causes are for the sake of others. This "for the sake of which" formulation grounds observations made of phenomena within a valuation scheme of antecedents. That is, from establishing the manner by which phenomena are linked Aristotle then continues to examine the ordering of phenomena according to their relationship.

For example, just as some phenomena are for the sake of larger phenomena, it follows that some arts are subservient to other arts. This section will examine relevant passages from Book VI of the Ethics as they pertain to the unfolding recognition of the relationship between art and man. Aristotle identifies intellectual virtues as stemming 
from the soul, and that, recalling Hadot's observations on Promethean and Orphic stances regarding nature, they are rational and either calculative or contemplative. The former stance suggests an orientation that seeds a perspective that will eventually become selfconsciously oppositional with Bacon. However, this is not an ontological reorientation regarding nature so much as an epistemological shift that can result in correct reasoning leading towards an understanding of truth.

Rather than establishing a dyadic opposition between these two ways of thinking, Aristotle argues that a contemplative approach allows for the cultivation of knowledge and, in a political sense, opens the way to correct decision-making (1139a10). Again, as I will show later in the essay, modern thinkers will reorient these intellectual stances by placing calculative thought as superior to contemplative vis a vis utility and production and then further by positioning calculative thought as directly responsible for securing man's estate safely from nature.

Aristotle situates his examination of techne in the Ethics between episteme and phronesis (Greek: $\varphi \rho o ́ v \eta \sigma i \varsigma)$. As knowledge is always teachable, and what is known is learnable, Aristotle asserts that having knowledge of something is demonstrable both to oneself and to another (1139b19). The aspect of demonstrability results in the creation of permanent works or the maintenance of certain phenomenological states. For example, demonstrating techniques of chair making can result in chairs, just as the demonstration of medical arts can result in health.

The demonstrable characteristic of phronesis is concerned with unchanging observations, such as with mathematical proofs. These observations may be concerned with broad matters about living well, or of something particular for which there is no 
definable art (1140a29). That it is practical means that it is concerned with worldly human matters that are demonstrably good or bad.

Techne is situated between knowledge and practical judgment because the products of techne are dependent, on the one hand, upon knowledge of the subject matter and, on the other hand, the decisions made regarding the results of action. Phronesis has to do with situational judgments and decisions; thus, phronesis factors into the actions of techne when a situational decision is called for, rather than during considerations of the overarching methods of a certain techne. The blueprints for a house or the recipe for a meal require situational judgment when conditions have diverged from the recognized plan; sound judgment will recognize appropriate responses and alternatives.

Aristotle asserts that phronesis is a virtue while techne is not because the sorts of judgments made according to phronesis are concerned with things of the world that have the potential to be otherwise, in other words, circumstances that allow for an outcome to be one thing or another $(1140 \mathrm{~b} 27)$.

Aristotle's statement about self-sufficiency in nature reveals the place of techne with man's relationship to nature. Though perhaps couched in hyperbole, man alone in nature is either "a beast or a god" (1253a27) because such a man lives beyond the boundaries set by justice, both literally by the walls of the polis (Greek: $\pi$ ó $\lambda \varepsilon 1 \varsigma$ ) and figuratively by the absence of religious and political tradition. Man living beyond the bounds of nature is no man at all because he no longer dwells in the hierarchy established within the cosmos, instead living apart from rational ordering within the wilder ambiguity of nature.

Techne furnishes man with tools that, while initially alleviating the challenges of 
nature, are just as quickly reversed and made the tools of injustice. When Aristotle writes that the first legislator is responsible for a cities greatest good, it means that the legislator has established the initial boundaries of justice, staked out, as it were, in the unregulated flux of nature; these boundaries in turn furnish man with additional tools to establish safe harbor within the city as well as provide the means for pursuing the good life. The emergence of the polis allows man to cultivate the world around him, through the making and use of tools, that in turn result in his entering into the ordered hierarchy of the cosmos.

Man is born with the innate capacity to develop tools that help to cultivate virtue and prudence but that just as often are turned towards the opposite of these (1253a32). Aristotle clearly recognized that techne could assist man to leverage his innate capabilities for the attainment of specific ends, especially when it concerns the satisfaction of food and sex needs. Without the virtue and justice to curb the worst of human behaviour man becomes worse than an animal. Without proper application of techne for cultivation of the growth of the polis, man is limited to a life that is "the most unholy and the most savage."

Nichols suggests that with Aristotle technical innovation must be tempered by political rule, however, as I will show in Chapter 2, this is inverted by Bacon's vision of a society founded on principles of technological advancement. Nichols also notes that when human passions are permitted to vent they may, in conjunction with techne, result in the limits of moderation set by justice to be surpassed (Zinman et al., 1993: 39). For the ancients, justice sets the standards for what moderate human action consists of. However, this limit for the ancients transforms into a benchmark that for the moderns 
signifies success when surpassed; in other words, man's natural limits lose their inherited fixity, thus acquiring a degree of ambiguity that modern technology assists in exceeding.

The philosophical fabric established by Aristotle is unwound and re-stitched by Bacon to form a new tapestry upon which man writes his ownmost destiny in the world, irrespective of the limits discovered both in external nature and internal human nature. Recreating his own definition, modern man in turn affects his own goals beyond such limits. Man's limits were apparent to the ancients as well but the paradigmatic philosophical position asserted that man's natural place was reinforced by his observations of the cosmos. Modern science allows for the discovery that man's place is not at the center of the cosmos but is rather situated peripherally. This introduces a sense of arbitrariness regarding man's place; discovering there is no divinely ordained hierarchy, then there is no reason to refrain from questioning the assumptions that led man to his present circumstances. The doubtful questioning introduced by Enlightenment philosophy opened the doors to the possibility of reevaluation and change of political circumstances. 


\section{Chapter 2: Cartesian Certainty}

This chapter begins by examining Bacon's rethreading of Aristotle's account of nature, calling for a new approach to the study of phenomena. A new epistemology to describe a world that man increasingly comes to dominate through increasingly refined technology. With a new epistemology in place for describing the world, Descartes establishes new axioms, irreducible and unbreakable, upon which further developments accrue. It's difficult to describe the influence of Cartesian metaphysics without slipping into hyperbole, so a brief examination of the core elements of his first philosophy will be explored in laying the foundation for an examination of modern science. This is necessary to properly address Heidegger's critique of Cartesian ontology as preparation for his own assessment.

This chapter concludes with an examination of Hobbes, with particular attention to the introduction to the Leviathan in consideration of Aristotelian causality. Hobbes' application of modern science to political order grounds further examination of technology in so far as a framework for political activity is developed according to technological principles. However, in creating the conditions for political order based on purely rational assumptions, the modern West is decisively shaped; Nietzsche's diagnosis reveals a link between modern technology and the will to mastery over nature.

Bacon's project is, in part, grounded on a critique and revaluation of the Christian Aristotelian tradition as received up to his time. He inverts several key Aristotelian principles to construct a new understanding out of old ideas. Aristotle describes a 
philosophical investigation into nature with the Organon, while Bacon revisits that investigation with his New Organon, a work that both criticizes and attempts to improve upon. The philosophical tradition of Aristotle received from the Scholastics carried too much theological baggage aimed at placating a perceived threat to religious powers, considerations that Bacon sought to shed while also attempting to salvage and refine certain aspects of classical philosophy.

The concern expressed by the Church in response to the discovery of Aristotle's writing is well-founded; Aquinas' attempt to reconcile the worth of human reason in the face of received revelation from God was invaluable in preserving the texts, but in turn formed a tradition that subverted the rational arguments expressed by Aristotle. Bacon levels his critique squarely against the Christian structure that had grown around the original texts. Until the Renaissance, the Scriptural account of the world was the most common and the most important. Bacon may have foreseen the immensity of an attempt to introduce a new way of thinking about the world, one which would necessarily entail a multigenerational perspective.

Aristotle's description of knowledge provides a quintessential example of classical ontology, in that knowledge of the world is bound up with the experience of the world. That is, what is known is not reducible to austere facts separated from their material source; rather, Aristotle asserts that knowledge is manifested as an active condition within the soul that is self-reflectively certain and demonstrably teachable (1139b31). The relationship between knowledge and making are distinct modes, with primacy given to reason because it governs making and acting.

Bacon inverts this definition by transforming the requirements for the definition of 
knowledge. Instead of a condition of the soul grounded in the experience of the world, knowledge is instead isolated and reduced to observable and measurable phenomena, whereby facts combine to form more complex structures. One possesses knowledge when they can describe the constitutive elements and procedures that come together to produce it; thus, knowing and making are collapsed together in the modern project.

Bacon insists that establishment of primary axioms and principles are the highest goal of scientific knowledge because this allows for new observers to employ them in their own experiments. Redefining knowledge and dissociating it from the thinker results in re-characterization of what it means to be knowledgeable. Instead of the classical ideal an individual possessing knowledge across a range of fields with the expectation of an ability to articulate a coherent description of the cosmos, bound to way of life that allows for uninterrupted mediation upon timeless themes. The classical philosopher could be expected to hold forth on many topics, each of which may have been tied to a broader understanding of nature and the cosmos.

The new epistemology articulated by Bacon favours specialization and experimentation within a narrow provision of circumstances; knowledge is migrated away from the individual towards a shared understanding. Documented procedures would allow specialists to conduct their own experiments, borrowing methods developed by other thinkers, ultimately resulting in an infinite ladder of advancement for the limitless pursuit of knowledge. The fourth step in his Great Plan describes a "ladder of the intellect," inverting yet another image of classical philosophy (Bacon, 1999: 76). Diotima's ladder in the Symposium describes an erotic ascent towards wisdom, guided by virtue, which for Bacon transforms into an accumulation of scientific facts divorced from 
the human drive to understanding. The erotic pursuit of wisdom described by the ancients warps into a materialistic quest for the attainment of scientific discovery and recognition from scientific peers. As seen in Bacon's re-writing of the myth of Daedalus, classical ideas of virtue are displaced by envy as a principle that facilitates the advancement of knowledge.

The notion of charity is another example of how Bacon inverts a traditional notion of virtue while simultaneously placing it in the service of scientific advancement. The unlimited pursuit of charity eventually leads to catastrophe for the person engaged in the activity, such that the giver will eventually dispose of all assets resulting in his destitution. However, in this example, destitution would allow for the possibility of new knowledge. In a parallel argument, Bacon acknowledges that the unlimited pursuit of knowledge will also result in errors but because these errors will provide further understanding for all mankind then this pursuit should be encouraged, even if it leads to catastrophe for the pursuer. Elsewhere in the Preface to The Great Instauration, Bacon indicates that knowledge is the only possible result after all possible errors have emerged (Bacon, 1999: 75).

In yet another twist on classical philosophy Bacon draws on Plato's image of the cave in The New Atlantis. Rather than emerging from a dark place of ignorance to discover and partake in the eternal Forms, hermits descend into them and from whom are received knowledge "of many things" (Bacon, 1999: 262). The hermits dwell in solitary, toiling in the dark to inquire into many topics, independent of outside interference; rather than seek the eternal beyond the world, the modern project seeks to determine particulars within the world. 
In The New Organon Bacon twists the metaphor in a different direction, in which "idols of the cave" represent the particular situation of individual ignorance, a precursor to formal Cartesian certainty (Bacon, 1999: 96). Instead of a single, shared domain of confusion according to Plato's metaphor, each individual is lost within their own deluded and misinformed understanding of the world. Each cave is particular to each individual, based on his or her own particular circumstances and abilities of perception or education. Each cave, and each individual lost within it, describes a myriad of forms of ignorance ranging from cultural hubris to false reasoning.

Instead of enlightened wisdom resulting from departure from the cave and observing nature as it is, in the Platonic sense, Bacon undermines this according to the dictums of his project. Man will indeed experience wisdom upon departure, not in observing nature as it is, but in realizing man's fullest capacity in his relationship with nature, that is, a relationship of dominion over and apart from nature. "Experiments of light" lead to the establishment of axioms and principles that inform methods leading to further experimentation and discovery. These experiments seek to establish understanding first and invention only afterwards, rather than "experiments of Fruit" that seek to win satisfaction of a particular thinkers curiosity; the former benefits all humanity whereas the latter benefits only a particular thinker (Bacon, 1999: 110). The former carries a long-term benefit, whereas the latter only short-term in so far as a particular thinker is concerned. The metaphor carries Bacon's re-conception of nature objectified and acted upon, providing the groundwork for a new understanding of the world.

Bacon's plan for the establishment of a society grounded on scientific rationalism, The Great Instauration, consists of several components that countermand the scholastic 
Aristotelian tradition. His grounding is based on an interpretation of nature, whereby the observable world conveys appearances but, based on his redefinition of knowledge, cannot be understood on observable grounds alone. His inquiry differs from the classic approach in three ways, which I will address in order: the initial point of inquiry, the order of epistemological demonstration, and the ends arrived at. I will examine each in turn regarding their difference from the articulation of Aristotle as evinced by the scholastic tradition.

The initial point of inquiry concerns the role of experience in the conduct of observations on nature, what for Bacon is "natural history." This experiential component may be an early iteration of the logical-positivist assertion of falsifiability, in that facts can only be said to be true not by demonstrating that they are so, but in the attempt to falsify them and, coming up negative, necessarily presuming their truthfulness. His formulation of natural history encompasses all experiences of man to "give light to the discovery of causes," as these will furnish axioms that in turn provide for further experiments. How things work is revealed when nature is "under constraint and vexed" and that nature reveals itself further "under the vexations of art than in its natural form" (Bacon, 1999: 82). Thus, purposiveness is revealed in the technical arts.

The second component of Bacon's plan concerns the purpose that experimentation ought to lead towards. He takes up Aristotle's assertion of the weakness of inductive reasoning, in that it is susceptible to counter-factualism. For example, a single black swan counters the statement that all swans are white; the weakness is that true induction is possible only when all available evidence is accounted for. Bacon asserts that inductive reasoning is superior because it can save time and effort by establishing 
universals from particulars; he defends his position by establishing an approach to the study of nature that divides and organizes observable facts about nature. This approach necessarily entails a position of acknowledged ignorance on the part of the observer, in that the observer can only realistically make a finite number of observations; it is up to succeeding generations to continue the work of experimentation, building on past experiments.

The summary of the ends of his method, regarding the control of nature, is worth quoting in full from "The Arguments of the Several Parts":

"For the end which this science of mine proposes is the invention not of arguments but of arts; not of things in accordance with principles, but of principles themselves; not probable reasons but of designations and directions for works. And as the intention is different, so accordingly is the effect; the effect of the one being to overcome an opponent in argument, of the other to command nature in action." (Bacon, 1999: 77)

Whereas Aristotle sees nature and art mirroring one another in their purposiveness, Bacon asserts that the goal of art is the control of nature. This is why Bacon denies Aristotle's definition of knowledge as linked to the individual; it directly benefits only the individual rather than all mankind. Moving knowledge into a shared domain allows for a multitude of efforts and experiments that will potentially bring indirect benefits to all.

Descartes formalizes the alienation from nature first hinted at by Machiavelli and which is later systemized by Hobbes. He accomplishes this by reifying observable properties of the world and distinguishing them from the initial assumption of a unitary quality of human will, in contradistinction to the classical description which is recognizes competing drives. Doubt is the fulcrum over which the tipping point into modernity falls 
into unlimited application of empirical analysis. I examine Descartes' contribution to the modern approach of formalized observation and how this lays the foundation for what eventually emerges as cybernetics; a conceptual framework for recreating adaptive environments, which consist of a discreet separation of processes and feedback mechanisms.

Descartes also formalizes the issue of doubt and trustworthiness regarding daily experiences and observations of the world. Our beliefs about the world come to us through sense experience of the world but sometimes our senses deceive us or are deficient; thus, measurable phenomena are mathematically provable and contrary to how we perceive the world (Descartes, 1960: 76). For example, the earth is perceived as flat but is geometrically measurable as spherical according to the emerging field of optics. Thus we can't entirely control ourselves from entertaining false beliefs about the world because beliefs are formed within our mind. From this, Descartes asserts, natural sciences are susceptible to error during measurement of phenomena; tools can't provide perfect measurement and are, to a degree, dependent on the accuracy of their manufacture. This leads to Descartes to assert that doubt can be expressed towards all experience with the physical world; the only experience not subject to this are those pertaining directly within our mind.

There is a sense of the "artful" with Descartes' interpretation of nature, that our experience of nature is one of deception. For Machiavelli, nature is a dynamic force that favours boldness and a constitution habitually bred to both withstand fortune and adapt to the unforeseen; touching is the requirement for knowing. For Descartes, on the other hand, nature is a dreamlike uncertainty that only appears to be within reach, but that even 
our sense of touch must be doubted in favour of an intellectual apparatus of logical certainty. This illusion of separation from nature is manifested as well in Descartes identification of the "new Archimedean Point" of observation construed as truths reached through an apparatus of logical certainty (Descartes, 1960: 81).

Like Bacon, Descartes' reference to the myth of Archimedes is a positive affirmation, in that the myth suggests an approach to the pursuit of truth independent of the limits set by the gods or nature; rather than a cautionary tale of excess, Archimedes represents an ideal to be emulated (Descartes, 1960: 81). There is no sense of urgency present in the Cartesian reading of Archimedes, as there arguably is with Bacon, because of his account of man's inherent separation from his experience of the world and, consequently, man's ability to correctly ascertain the truth.

Descartes rejects Aristotle's formulation of man as a political animal, charging that instead of answering questions about human nature it rather creates more questions (Descartes, 1960: 82). Nature is associated with bodies, the veracity of which are difficult to ascertain, thus human nature is also rejected as a viable entry point into philosophy inquiry. Knowledge is not obtained by empirical observation alone, as Aristotle suggests, nor is touch sufficient as Machiavelli suggests; rather, only by thinking towards truth from indivisible core principles can truth be ascertained universally.

Descartes asserts that all modes of thought reside within the mind independent of the factuality of the world; we can, for example, imagine Santa Clause despite the lack of factual truth. Despite factual evidence an idea can nevertheless be true in itself; we can entertain any number of notions and in doing so the idea itself operates independently of 
falsifiability claims. The question of whether the world conforms to our ideas about the world is the entry point of falsifiability.

Judgment emerges in the question of determining whether our observations of the world are true or not. Whereas the classical account of phronesis is concerned with matters that carry an implicit trust of the realness of phenomena, from which are determined matters deemed good or bad for life, Descartes' doubting of phenomena induces a transformation of the place of judgment in the experience of the world. Judgment is directed away from worldly phenomena and directed inwardly towards an assessment of whether our ideas about the world are true or not. In doing so, Descartes reduces judgment to a mental process striped of political significance and ascribes it the role of fact-checker for how we navigate the world.

Descartes distinguishes between two sources for our ideas about the world, the first is nature and the second is the self; the first engenders inclinations for the second, that is, our beliefs about nature. According to Descartes, man has a blind impulse to ascribe properties to things in the world (Descartes, 1960: 96). This contradicts Aristotle's assertion of observation based on sense-experience, a point that Heidegger will defend in his critique of Descartes and which will be examined in Chapter 3.

By separating the mind from the body and displacing man's experience of nature as purely external phenomena, Descartes succeeds in establishing an ontology of the world based on its lowest common denominator, that is, phenomena represented by substances. This leads Descartes to assert that substances represented by ascribed properties carry more objective reality than those of modes or accidents; that is, temporary properties are less real than the eternal, and finite properties are less real than infinite. This is his 
rationale for the existence of God and it seeks to provide underpinning for the temporal quality of nature ascribed by the moderns. Rather than the cyclical recurrence described by the ancients, nature is instead depicted as a permanent progression of seasons.

By grafting perfection to permanence, Descartes argues that ideas can acquire an objective reality derived from antecedent causes, which in turn are equally or more objectively real. This begins a process of reification of ideas that characterizes modernity. Tracing antecedent ideas that possess greater degrees of perceived objective reality eventually leads Descartes to postulate an archetypal "first idea" as the cause for all subsequent ideas. Like Aristotle's "first mover," a primary antecedent cause is cited by association with God. Thus, God represents the ultimate reification of thought and a principle example of what Heidegger will later critique as "fallen-ness from Being." This example also serves as an early form of what will eventually become commonplace in cybernetic theory, that is, the idea that a conceptual framework can acquire the property of objective reality independent of world factuality; I will return to this issue in Chapter 3.

Descartes constructs an ontology in which properties of the world are represented as substances and that substances are inherently contained within phenomena, but that we only have observable access to the attributes of substances. By separating forms into discrete substances Descartes succeeds in reifying the multiplicity of nature first articulated by Aristotle (Descartes, 1960: 129). Recall that Aristotle begins this by associating motion with nature and then extrapolating multiplicity from nature.

Descartes predicates mind-body dualism according to two primary considerations, the res cogitans and the res extensio, that is, thinking beings and physical beings. A thinking 
being is not extended into physical properties, whereas bodies are extended beings that don't think (Descartes, 1960: 83). Crucial to his articulation is the dependency of properties as substances. Thus, mental faculties such as imagination or perception are intelligent substances that adhere to the body, possessing no intelligence.

Descartes' suspicion concerning the link between imagination and the senses lends weight to the crucial distinction between truth and falsehood. As Hobbes will later echo, senses are inherently fallible and merely allow access to ascertaining certainty in phenomena. This leads to a bifurcation in thinking that both privileges the Platonic adherence to the permanence of truth and denigrates sensual experience; in other words, sense-empiria is necessary but not sufficient. When the permanence of truth, discovered through modern rationalism, is coupled with Hobbesian science what emerges is the reification of political order. Cartesian ontology asserts that thought is non-temporal and therefore closer to the eternal; politics conceived as a representational system of order results in a conceptual permanence that eventually leads to bureaucracy, stability, and security. This ordering is accomplished, in part, through developing the intellectual tools that allow for mastery over nature.

Unlike Machiavelli's emphasis on withstanding fortune and the nuanced challenges associated with mastery of it, Descartes transfers the object of mastery from nature to the individual (Descartes, 1960: 20). The theme of mastery over human nature is first intimated in the Republic but Descartes narrows the focus from man in the broad context of the polis, to the scale of the particular individual. This narrowing of focus is how Descartes establishes primacy of the mind over the body; furthermore, by honing in on the scale of the individual the political implication transforms from men of a particular 
nation into men of the supra-national, that is, Descartes has prefigured Kant's cosmopolitan man by establishing the ground for men of rational Enlightenment.

Machiavelli's emphasis on withstanding forces of nature introduces the initial premise of alienation from nature; this distancing eventually leads to the overt mastery over nature that Bacon will eventually champion. Descartes, however, levels mastery at the scale of the individual. This articulation of mastery over nature would be bizarre for the ancients, for whom nature should be adapted to and for whom the individual is secondary to the polis. Descartes' third maxim in the Discourses "was always to conquer [myself] rather than fortune" (Descartes, 1960:20). The political fulcrum is consequently displaced to the individual resulting in a narrowing of the arena for political concern. Likewise, just as the political spectrum narrows from the polis of the ancients to the agency of the individual in modernity, Descartes narrows the ontological distinction between what is human and what is natural. What is human is limited to the mind and the conscious thoughts available to an individual, whereas what is natural is not only "the environment" of the natural world but also all physiological functions along with feelings of desire, pain, etc. The human mind is thus hived off from the phenomenological world as the only legitimate context of rational orientation, irrespective of factors that inform an experiential understanding of the world.

Descartes' articulation reduces understandable phenomena to observable facts, such that the world can only be understood on factual grounds; that is, only that which can be measured can be understood. Properties of measurement are, literally, the extensions of things in the world. In Descartes' formulation res extensia consist in that which extends into the world and which can be observed and measured. In this articulation the world is 
everything that we measure it to be, according to its observable characteristics. The more precise the methods of measurement and determinability the more precise an understanding of the world will follow. The capacity to closely examine, with the most precise tools and methods available, in turn provides the most exact understanding of the world.

For Descartes, properties acquire permanence in so far as they represent their qualities independent of observational status. Regardless of whether an observer can identify the qualities of phenomena, such qualities will exist. Under no circumstance can qualities represent alternative truthful meaning besides their perceived qualities, in so far as they can be perceived accurately. The degree to which senses may accurately perceive properties is incidental to the properties themselves.

I will argue in Chapter 3 that the Cartesian assertion of permanence, in so far as it may apply to a self-referential cybernetic system, results in reification of the constitutive elements of the system. Heidegger's critique of Descartes will be explicated considering his critique of cybernetics, in so far as the question of Being can be raised in a selfreferential system. Nature is displaced as the referential context of phenomena, supplanted by a system of circular logic and feedback. Qualities of the system are manmade, produced by artificial language constructed from the feedback of other systems.

At this point it is necessary to examine Hobbes. Early iterations of cybernetics have referenced the Leviathan as the first and most obvious expression of the self-organizing system, represented at the scale of the state. The image of a gigantic, artificial man 
composed of smaller men, independently organized in themselves but co-active with all the rest, is the archetypal metaphor for a cybernetic society. The symbolism of the image supports the overarching Enlightenment characteristics of the victory of materialism over theological doctrine; after all, it is a mortal god that wields sacred power, rather than a divine god wielding earthly power.

Hobbes' formal systemization of politics begins where Descartes Mediations end, with the creation of representational structures of political order. The Leviathan is the first modern example of reified concepts made permanent through political expression. What Hobbes introduces, and what grounds the crucial leap from Descartes, is the extension of modern physics into a formal system for understanding political order. This is arguably the first formal model of cognitive science and lays the foundation for advances in the field in the following centuries. It also suggests the earliest iteration of cybernetic principles applied to politics, in that political order is transformed into a selfsustaining system capable of adapting to input from its own feedback mechanisms. I will demonstrate this through close examination of Hobbes' arguments.

The introduction to The Leviathan begins by redefining the relationship between man and art by reassessing man's nature. Hobbes accomplishes this by draining the traditional privileging of man, a being at the center of creation, such that the essential composition of man is nothing divine so much as matter defined purely in terms of physics. Aristotle draws a link between man and the divine by tracing the internal motions of human movement to a theoretical "first mover." Hobbes severs Aristotle's connection by ascribing internal motions using the language of modern physics rather than the divine; doing so allows Hobbes to redefine life in terms of observable phenomena limited to the 
motion of limbs and random forces in nature acting upon matter.

The introduction consists of four paragraphs that draw heavily from Aristotle's four causes, employing his model of reasoning but applying it in a new way. The opening paragraph uses the language of physics to redefine the nature, the matter from which man makes himself. The formation of the state, symbolized by the Leviathan, is done so from the base materials of man. The state emerges out of man, though man is still present within it. In portraying the Leviathan in the shape of a man, Hobbes explicitly agrees with Aristotle that the state takes its shape from its core material, man, and a material that also determines the finitude of shapes available to it.

There is an ambiguity to Hobbes' formulation of political order. While the chief aim of his political work is to provide instruction on how best to mitigate the worst aspects of human nature in favour of political security and order. His advocacy of channeling the martial desires of spirited citizens towards mercantilism rather than military glory allows for constructive energies directed back into the state; the beneficial qualities that in turn contribute to modern laissez faire market economy is clear. However, it can be argued that his formulation also allows for the emergence of such modern extremes as the mechanized totalitarianism of Stalin.

That automata are devices that move themselves is sufficient for Hobbes to suggest, "Life is but a motion of limbs" (Hobbes, 1994: 3). In other words, man is the matter upon which he makes himself. There is a mechanical logic at work in the construction of

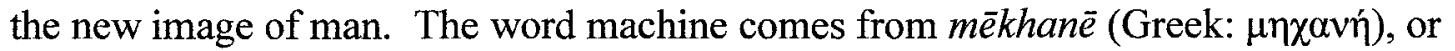
trickery; therefore, to devise a machine is to find a way to trick nature (Hadot, 2006: 94). The form of the state is conceptually modeled from man, whose constituent biological 
functions are replaced by man-made mechanical contraptions (springs, levers, etc.). The word engine originally derives from the Latin ingenium, meaning talent or device; it connotes ingeniousness and cunning and the term was applied to machines as early as the seventeenth century. This makes for a curious etymological connection when "mechanic," or trickery, is employed in conjunction with "machine," or device; thus, modernity pushes trickery over nature one step further through construction of ingenious devices that perform trickery on behalf of man. Cybernetics is the next step, with the creation of machines that in turn create themselves; consideration of what this means for political order will be addressed in Chapter 4 .

Hobbes replaces God with an artificer, a divine master of arts, instigator of tricks against nature, inverting the benevolent God of the Christians into a master craftsman of engineers and makers. If man is the self-made automaton in perpetual motion then it follows that a master artisan created him. However, the sentence is a question, which asks whether such life was intended; Hobbes answers by indicating, "Art goes yet further," imitating man. By stating intent as a question Hobbes undermines the purpose set forth by the Church; by answering the question of purpose as art that furthers man, he establishes the trajectory of his argument.

The purpose at work in the creation of an artificial man as a state is for the purpose of nation ruling. The Leviathan is for the sake of man a public creation, in which man builds himself according to needs that are greater than his own but serves his interests in a limited way. However, where Aristotle asserts that teleological purpose can be observed in nature and in man's works, Hobbes removes nature from the equation and limits purpose to human intent; he accomplishes this by collapsing the first and third 
causes together.

Hobbes' reasoning concerning the intractable necessity of fear within man is characteristic of the modern method of determinative thinking. Hobbes recognizes the permanent characteristic of man at the foundation of all politics, namely, fear. In transferring almighty fear of the divine and other men upon a titular sovereign, Hobbes establishes a level of assurance that operates on a predictable feature of human behaviour that has the effect of allowing for the possibility of peace. Determining in advance the symptom and solution to a perennial political issue, Hobbes commits himself to the modern metaphysics of framing the possibilities of human conduct and arranging in advance the solutions best to deal with it.

Hobbes' articulation of reasoning is grounded in a determinative stance, such that the activity of reasoning is based on reckoning derived from the analysis of meaning that man ascribes to phenomena (Hobbes, 1994:22). Establishing the boundaries of meaning is an act of authorship; to define is to engage in the drawing of meaning around phenomena. Whereas Aristotle's method is to separate truth from falseness in the observation of phenomena, Hobbes removes the quality of inherency in truth from phenomena and instead asserts that meaning is merely that which we proscribe, effectively agreeing with Descartes. Meaning discerned in phenomena, ordered in advance according to the measured precision demanded by modern mathematics, allows for a forecasting of order applied to the measurements of social order.

The nervous system of the Sovereign constitutes a feedback system that provides information that is to be decided and acted upon according to precepts determined in advance. The decisions that follow then allow for a homeostatic adaptability predicated 
upon the assumptions built into the system, most notably in this case the experience of fear in man and the observable tendency to act towards self-preservation and security. Creation of an autonomous system capable of adjusting its native elements to account for flux in the surrounding environment is an aspect of the project of modern science, broadly speaking, and a cybernetic system applied to society, coupled with the promise of mathematical certainty, is the ultimate realization of political security.

The metaphor of the Sovereign as mortal god representing, ostensibly the English, is also broadly taken to refer to any given industrial power of the time, not limited to the likes of Spain, France, etc. The metaphor is seen to parallel one of the tenets of secondorder cybernetics, namely, organizational closure. Cybernetic systems are built to operate independently of other organizations, except in so far as is necessary for their operation or is situationally incidental. Hobbes' vision of the modern state coincides with just such a formulation, in which any given sovereign acts independently of others, capable of adapting to its own exigencies.

Describing the inner workings of the sovereign as a series of interrelated subsystems further parallels the conceptual framework of cybernetics. Each subsystem is capable of acting relatively autonomously, whose dependency on other subsystems is realized indirectly through organizational enclosure through immersion within the sovereign-state. Creation of the modern state, in so far as it is a mortal god, follows from articulation of the core axioms of modern science. Existence within the modern state allows for a clear articulation of safety at the expense of abandoning a life situated existentially closer to the state of nature.

Enlightenment science inaugurates the onset of politics represented rationally and 
systematically. The dismantling of Scholastic Aristotelianism, considering scientific discoveries and axiomatic principles, begins a steep trajectory towards abstract systems and political order based on predictable stability. This stability comes at a price, Heidegger will argue, because the philosophical stance that gains primacy is only one way of thinking and acting in the world. Establishing political order based on the axioms established by Bacon and Descartes, and articulated politically by Hobbes, results in a narrowing range of possibilities. Rather than free man from the limits imposed by religion and tradition, the liberal freedoms championed by the Enlightenment constitute a way of living that further distances man from other possible ways of living.

As will be seen in the next chapter, Heidegger develops a powerful critique of Cartesian ontology but offers few solutions to the technological society that has since emerged from the groundwork laid by Bacon and Descartes. Rather than providing a sound solution to the challenges of modernity, Heidegger's philosophy instead points the way to an even more immoderate set of notions that, arguably, leads modernity deeper into the morass that Heidegger warns of.

Cordoning off man's direct experience of the world by erecting an ontological structure between the mind and the world, in conjunction with a method of observation grounded on indivisible axioms, results in an articulation of unassailable certainty. What can be challenged is done so through a rigorous method that must match its own plan. The modern era constitutes a multigenerational project that, initially, seeks to identify all observable phenomena and cultivate the means for ensuring man's security.

This project carries unforeseen consequences for Western civilization resulting in a strengthening of the Cartesian ontological framework that, in conjunction with the 
collapse of religious authority, results in the formalization of mastery over nature, formal in the sense that philosophical and political systems emerge as universal explanations for phenomena. Mastery of nature emerges as the goal of science, not only of the natural world but of human nature as well. 


\section{Chapter 3: Heidegger's Questioning}

It is with Bacon's call to mastery that the modern era defines itself. Mastery of nature emerges as the task of modern science, a task grounded on certainty and the absolute precision of a world ordered according to modern physics. The ordering of man's understanding of nature according to physics is one aspect of Nietzsche's critique of modernity, particularly as it relates to industrial society. I provide an introduction to Heidegger by way of Nietzsche's examination of modern science and the mastery of nature. His insight provides valuable grounding for Heidegger's analysis of technology and why this is meaningful for the emergence of cybernetics.

Nietzsche's questioning concerning modern science begins an inquiry into the assumed validity of physics that Heidegger then sustains in his ontological analysis of modern technology. Nietzsche suggests that modern physics may only be an interpretation of particular form of phenomena, that which can be ascertained by the senses. Nietzsche suggests that absolute certainty in the observable phenomena of the Kantian "thing in itself" rests on a faith in opposite values (Nietzsche, 1989: 10). The drive for philosophical knowledge is based on a will to power that is in turn grounded on a primordial condition masked by the assumption of universally valid knowledge.

With the flourishing of modern science, grounded on Cartesian principles of certainty, philosophy is then reduced to the status of an analytic tool at the disposal of the scientific project. Baconian mastery of nature requires the strictest precision in the ordering of knowledge and the philosophical tradition provides just such a rigour. When philosophy is reduced to a "theory of knowledge" the aims of inquiry are lowered to the perspectival horizon of immediate needs (Nietzsche, 1989: 123). 
Bacon had already asserted that modern science must become increasingly specialized and compartmentalized, as doing so would ensure greater efficiency in determining the object of inquiry. Specializing in narrow fields of inquiry precludes the necessity to acquire wide breadth of knowledge, thus allowing for increased focus on one's specialty. Nietzsche counters that doing so creates new conditions that fail to cultivate a perspective of sufficient "height" to understand the deepest significance of philosophical inquiry (Nietzsche, 1989: 124). Thus, science flourishes at the expense of philosophy; the lowering of philosophical inquiry to the satisfaction of scientific demands results in the transformation of philosophy into mere analytic thinking. Whereas the goals of classical philosophy aimed beyond mere sense perception, modern philosophy serves the needs of a skeptical modern science that disregards what is beyond sensory verification.

Scientific mastery over human nature emerges from the inversion of classical philosophy's noble aims, Nietzsche argues, resulting in an elevation of bodily health as the highest concern of modern man. Control of human nature is the logical consequence, which is attained in part by "lifting the veil" of human nature and dissecting according to the dictums of the scientific method. Nietzsche suggested that the end of the age of rational man was at hand because the universal tenets of the Enlightenment were far from universal; its tenets cannot be maintained and the ambiguity in the core of modern science has resulted in catastrophic doubt that erodes even the possibility of ethical standards (Grant, 1969: 32). Belief in the absolute certainty of modern science allows for remaking man according to the image most desired; the axioms that this certainty rests on are the target of Heidegger's deepest criticism of modern philosophy. 
Heidegger's critique of the commonly accepted understanding of truth in philosophy gains traction first with Aristotle. Aristotle's examination of knowledge in the Nicomachean Ethics begins with the assumption that the distinguishing of truth and falsehood in knowledge can be ascertained by determining which predicates correctly pertain to what can be known (1139b21). This approach sets the claim that what can be known is necessarily so in perpetuity, such that only a change in conditions requires adjusting the predicate; in other words, truth does not expire in time. This apophantic format of assertions, even if true, carries ontological baggage that Heidegger will examine in the relationship between modern mathematics and modern metaphysics.

For Heidegger, the essence of modern science is mathematical. This observation is demonstrated through an etymological analysis of the Greek words mathesis and mathemata, that is, the act of learning and that which is learnable, respectively. What this reveals are the topics of focus most concerned with the mathematical: things that come from themselves, things made by man, things that stand ready at man's disposal, etc. (Heidegger, 1993: 274). Numbers are the most mathematical expression of what can be known of a thing that isn't otherwise a property of that thing; for example, in observing three apples I can understanding "three-ness" independent of all other observations of the apples in question. This reveals that mathematics forms the basis of what can be known, in that what can be known already begins with what we already know (Heidegger, 1993: 278). To repeat, mathesis indicates the learnable and what is learned.

Heidegger thinks this is problematic because this approach, rather than revealing 
truth, conceals it further by prefiguring the ontological conditions already present in our use of language, our expectations, and our understanding of the world. The most important contributions to philosophical thinking given by Aristotle and Descartes have, in a sense, "plastered-over" the possibility of arriving at the deepest expression of truth; Heidegger's criticism echoes Hobbes' critique of the Aristotelian Scholastic tradition, whereby the intellectual baggage of the method obscures, rather than reveals, the truth of things. However, Heidegger pushes this critique further than Hobbes by insisting that even modern science "gets it wrong" because its use of Cartesian assumptions also conceals truth, but in a manner that is different in conception, delivery, and result.

When Aristotle, and by extension Descartes, insists on the predicative truth established according to the observation of appearances then an understanding of the genuine phenomena taking place cannot be understood. The appearance of phenomena is only the outward manifestation of what is really happening; we typically confuse what is observably happening with the phenomena that causes the appearance under observation. This is what leads Heidegger to assert that phenomena are never appearances but rather that appearances always depend on phenomena (Heidegger, 1962: 52).

The way that Heidegger approaches a closer understanding of truth is through a consideration of the relationship between logos (Greek: $\lambda$ ófos) and aletheia (Greek: $\dot{\alpha} \lambda \dot{\eta} \theta \varepsilon \omega \alpha)$. Logos can point the way towards the revealing of truth but the use of language introduces the possibility of concealing it. The words used to describe phenomena, even if accurate in description, are constitutive of an appearance and as such constitute one step removed from the genuine revealing of truth. Thus, our use of language has a tendency to conceal what is really happening in phenomena. That said, logos is 
concerned with "letting-something-be-seen" and thus is available for expressing something true or false (Heidegger, 1962:56). Heidegger is clear that this expression can't simply agree with phenomena but rather must assist in unconcealment. Because aletheia carries the negative prefix $a$-, truth is revealed when logos can express in a manner that doesn't conceal what is.

Truth is not a statement that occurs at some "intersection" of logos and phenomena. Rather, truth is revealed when logos is careful enough not to further conceal it. This is why logos "stands apart" from truth; it indicates the way to the revealing of truth without standing in front of it, as an appearance, nor even as a representation of the truth. Heidegger's critique is that Aristotle has developed a method of ascertaining truth from falseness, however, this ascertaining conceals truth by establishing a judgment of phenomena wherein the judgment, in a sense, "stands in front of" the revealing of truth. This judgment constitutes an appearance, i.e., a surface manifestation that, as stated before, is not the phenomena in question. Thus, when a subject is given definite characteristics this constitutes its appearance, an appearance that represents what is observed and conceals what is actual.

The deeper phenomenon Heidegger is grasping at is notoriously elusive and resists absolute description, for to do so is to engage in precisely the confusion that Heidegger is criticizing in the philosophical tradition. The issue of truth revealing itself is crucial to the conceptual transformation that takes place with the Latin shift into veritas. The Latin tendency to establish certainty in speech, unlike Greek, which carries an ambivalence that allows for simultaneous connotations, establishes an expectation that language may convey truth concurrently with meaning. This is what leads Descartes to describe 
philosophy with core principles that cannot be reduced to ambiguity nor, like atoms, be reduced to smaller components.

Heidegger closely examines the foundations of modern scientific thought and the assumptions that this foundation consists of. He doesn't disagree that experimentation has been a facet of philosophical and scientific thought since ancient times, but does identify a difference in how facts and concepts have been perceived since then (Heidegger, 1993: 273). Concepts, and preconceptions, about the world are informed by the importance that thinkers place on the circumstances of experimentation.

Understanding Heidegger's critique of cybernetics requires an examination of his broader critique of modern science, as well as modern mathematics, in so far as they are grounded in the philosophical speculation of Descartes. Thus, from Descartes it will be clearer to what extent the issue of technology, and cybernetics in particular, is at stake for political organization.

Heidegger makes the argument that modern metaphysics arises from the inner characteristics of modern mathematics. Descartes is the chief source, and target, of Heidegger's examination, wherein the core principles established by Descartes are symptomatic of the manner by which modern metaphysics seeks to explain the world. What distinguishes ancient from modern science has less to do with an emphasis on concepts that are later substituted with an emphasis on facts, and more to do with how concepts and facts are conceived from the outset. As such, experimentation and measurement were just as prevalent with the ancients but their manner of execution and consideration of importance differed (Heidegger, 1993: 271). 
For example, in the examination of motion Aristotle asserts that any change of property constitutes a form of movement from one condition to another (201b8). The motion of bodies pertains to changes in how the body relates to itself from another place, thus a body moves according to its nature towards its natural place. How a body moves is inherent and natural to it; in other words, a body grows out of its nature. Its nature describes the limits and boundaries of itself. In this sense, nature is primary both as a cause and as a fundamental inquiry (201a10).

Newton's explanation of motion is at complete odds with the ancients. Nature and the inquiry into nature are reversed with the moderns, whereby the commonsense everyday experience of motion is rejected as inadequate; Newton's first law of motion is utterly counterintuitive and is based on an observation that is contradictory to experience (Heidegger, 1993: 288). Heidegger notes that modern science begins with a representation of phenomena that contradicts ordinary observation.

Thomas Kuhn describes conceptual advances in science in terms of paradigmatic shifts. Heidegger describes something similar, in that a new way of thinking about facts comes about neither accidentally nor arbitrarily. This leads Heidegger to claim that idealized mathematical ideas require a foreordained determination of phenomena, and ties into his critique of Descartes for having established a method that paves over a deeper observation of the world.

The modern mathematical project consists in determining, ahead of time, what lies at the basis of all phenomena. This involves first establishing a hypothesis in advance of the empirical observation, a hypothesis that must fit within the established framework of accepted science to "do science properly." This going ahead "in advance" is what 
Heidegger refers to as a projection of the assumptions of modern mathematics, which constitutes the fundamental characteristic of modern methodology (Heidegger, 1993: 289). The core principles establish an underlying grid of uniform coordinates, infinite in space, upon which observations of nature are superimposed. The grid in turn sets the possible ways of accessing the attributes of entities in nature, that is, the possible modes of questioning are predetermined according to the principles determined in advance; this precludes the possibility of questioning from the perspective of traditional inquiry. When entities are stripped of particular observations in favour of facts supported by the uniformity of measurement, then the mathematical character of thought leads to a narrowing of the definition of mathematics, i.e., from encompassing the learnable and the teachable to the identification of phenomena that match the express demands of uniform measurement (Heidegger, 1977: 121).

Heidegger's examination of the relationship between modern mathematics and the understanding of nature leads him to question the extent and limit of the justification of mathematics. Abandonment of traditional religious explanation was the first of many consequences following the emergence of modern mathematics. Heidegger characterizes this emergence as one that carries its own "inner drive" towards the realization of truth in its own terms, not only in the framing but also as foundation for further inquiry (Heidegger, 1993: 296). The self-grounding of modern mathematics is the first of two key principles that Heidegger identifies in the transformation of modern metaphysics, with the second arising in the articulation of Descartes' ego cogito, the "I" as a privileged subject.

By establishing mathematics as the foundation for inquiries into nature, Descartes has 
simultaneously established the foundations for inquiries into metaphysics. If mathematics can establish universality of verification, and metaphysics is tasked with the furthest inquiry into being, then it follows that modern metaphysics will yield inquiries whose scope is universal, whereby the truth yielded will have the attributes of universality and therefore permanence. The universality of mathematics is thereby reflected in metaphysics, which in turn becomes the authoritative source of knowledge. This authority was once the reserve of religious tradition but in modernity is severed and dissociated from the common everyday experience of the world, given its own sense of permanence irrespective of locally observable particulars or conditions.

It is not enough to assert that the scientific method articulated by Bacon is merely one of many conceptual tools for ascertaining the world and discovering truths but rather, according to Heidegger, forms the driving axiomatic principle for the acquisition of knowledge. As such these axioms capture distinct definitions of being, which might not be inaccurate in their factuality, but the definition has the effect of crystallizing one of perhaps many definitions of phenomena (Heidegger, 1993: 301).

The subject "I" acquires primary significance as the deterministic character of man, displacing Aristotle's formulation of the zoon politikon, on the one hand, and, on the other, the Church's articulation of man as God's creation endowed with reason.

Heidegger's critique of Descartes amounts to a criticism of the traditional approach to the ontological study of the world. The grounding of metaphysics in modern mathematical assumptions results in an ontology consisting of statements that are 
reducible to plain facts and predicates. However, Heidegger insists that this approach doesn't account for the meaning that man discovers in the world; in short, a "world" can't be built up from mere facts about the world, which means that any account of "worldhood" can't be made intelligible (Heidegger, 1962: 94).

The question of intelligibility is key for a discussion of worldhood because this is the manner by which the meaning between the interrelationships of entities can be explained. As stated earlier, Descartes' definition of the world is characterized by res extensio as "substance," either as an entity in itself or an entity as substance, that is to say, "substantiality." Substances are accessible through their attributes which each have distinct properties, the essence of which is described through extension (colour, size, shape, etc.).

Leaving aside the issue of God in Cartesian ontology, all other entities in turn require production and maintenance to have some property available for ontological analysis. The properties must agree with res extensia requirements to be indicative of some condition in the world; as such, production must be because of another entity that in turn must constitute an entity itself (Heidegger, 1962: 125). An interesting connection from Aristotle to Descartes emerges in Heidegger's analysis of apophantic sentences. Because Descartes" apophantic usage applies "is" to all phenomena, ranging from God to hammers, literally an infinite variance from the divine to the mundane, a uniform tendency arises that collapses the ontic weight of particular phenomena irrespective of their phenomenal variance.

The theological debates of Aristotelian Scholastics often argued by way of analogy to get around the problem of accounting for the characteristic of infinitude; that is, applying 
an ontical characteristic that matched the res extensia in apophantic structure to an entity purportedly infinite. The Greeks hadn't resolved the issue and Descartes merely dodged it by asserting that the characteristics of God were self-evident. Descartes justifies the inaccessibility of God's characteristics by establishing that all entities in themselves are inaccessible except only in so far as we can observe their attributes, but this results in positing an ultimate entity as present-at-hand from which follow all other entities (Heidegger, 1962:129).

The crux of Heidegger's critique of Descartes is in the constant present-at-hand quality of entities described by an ontology of res extensia. Modern mathematics is the foundation of his ontology because it is so well suited to grasping present-at-hand entities. The transcendental foundations of modern mathematics thus displace the traditional approach of the Aristotelian Scholastics. If entities in the world are understood as exhibiting attributes which are so accessible as to "go without saying," then the metaphysical presumptions about the immediacy of phenomena and the permanence of truth which may be attributed to them certainly does go without saying.

From this Descartes can assert that entities in themselves are inaccessible because the modern method of predetermining phenomenological attributes precludes the issue of absolute access. The modern mathematical method determines in advance the essence of entities, which solves the issue that Descartes posits first (Heidegger, 1962: 131).

Descartes recognizes that senses may assist in understanding the world but argues against relying on them. The senses between people vary in their precision, the moment of observation may be inconsistent, personal experiences can't be trusted, nor the common everyday experience of perceiving the world (Descartes, 1960: 88). This 
displaces the trust of common experience and moves it towards the permanence of mathematical precision and accuracy. This also undermines ontological predispositions of a given comportment towards the world because the verifiable truth presented mathematical representation of present-at-hand entities is so absolute as to preclude other possible ontological orientations.

Descartes analysis of properties through the senses is performed only as entities understood as present-at-hand, that is, as two more res extensia side by side. Thus his account of how to obtain access to entities is prejudiced by an approach that already posits all phenomena as extensions. By using only one kind of Being, the mathematical, all entities are apprehended as present-at-hand. This is not necessarily mistaken, as in some cases this may be perfectly accurate, however, this may well be inadequate for a richer, complete account of the world (Heidegger, 1962: 130).

This leads Descartes to construct his ontological understanding of entities purely in terms of res extensia, or substance. Thus, a deeper and more primordial analysis of the world is paved over and rendered inaccessible by framing the world with such characteristics. An element of Heidegger's critique of Descartes is in the implication that after getting to the plain facts of nature somehow it would be easy to build up a world. Descartes certainly allows for such a method but this does nothing to capture the issue of meaningfulness between relationships of phenomena.

Meaning is something we discover, according to Heidegger, we don't apply it to phenomena. Reducing the world to material facts does no explain the world in a way that is at all meaningful. For example, electrons and galaxies may be explained through Cartesianism but this does nothing to explain how man understands the world around 
him and figures out how to live meaningfully. Thus, the Cartesian approach of relying on thinghood alone results in an insufficient ontology that explains facts but not meaning. The doubt accompanying Cartesian ontology induces a clearing away of beliefs grounded on tradition and faith that, in conjunction with the absolute certainty of modern mathematics, results in the seizing of only one way of Being and only one way of ascertaining the world.

Heidegger's doubt arises first from calling into question the unreflective opinion of what constitutes technology. In relying only on the definition of technology as a neutral means for alleviating man's estate, the deeper understanding available for ascertaining ontological possibilities cannot be arrived at. Beneath the usual instrumentality of technology is an implicit assumption concerning the causality that technology both emerges from and in turn initiates (Heidegger, 1977: 6). It is interesting that Heidegger's analysis of the traditional Aristotelian causes is done so by their Latin translation; the Greek word for truth, aletheia, gives way to the Latin, veritas, which acquires the connotation of certitude and necessity, and which takes the first step towards the reification of forms first suggested by Plato. By using their Latin translation, Heidegger draws attention to the implicit assumptions of certainty that the philosophical tradition has given over to them.

Heidegger further flips the sequence of the third and fourth causes from their traditional order. By leaving the efficient cause for last he is able to move towards a closer examination of the traditional understanding of the essence of technology, that is, that which allows for making; it is the cause most closely associated with an effect and 
the modern concern of technology mostly regards effectiveness, efficacy, and speed. While the end cause, fourth in his arrangement, "is almost forgotten" it still remains as the cause which gives bounds to phenomena and which informs the purpose or the "towards-which" that is a cause; the first two remain bound together as co-responsible for the possibility of something coming into existence (Heidegger, 1977: 6).

Heidegger thus shows how a definition of technology predicated on instrumentality, in terms of causality, only conceals the truth of what technology really is. The four causes "herald" different ways of phenomena to emerge; the causes describe that which is responsible for the "occasioning of a thing," which in turn hints at the deeper essence of causality. For Heidegger, causality is what allows for phenomena to reveal themselves to observation (Heidegger, 1977: 11).

Heidegger's description of technology as a "revealing" runs counter to the most typical understandings of what technology is or how it comes about. To reveal is to partake in allowing extant phenomena to become observable, what Heidegger refers to as "presencing." Technology is often understood as the physical manifestation of applied physics or other science, consisting of a designated elaboration of procedures for the ensuring of some goal; or that technology is somehow discovered, as though the means provided by a new technology lay fallow in the expectation that an enterprising Prometheus would someday understand the necessary connections that lead to its articulation. Both circumstances can be true on occasion. But this is only the unveiling of means for the sake of newer means; rather, the revealing Heidegger refers to is concerned with the revealing of new possibilities for the Being of Dasein.

Heidegger asserts that these possibilities provide the grounding for the bringing-forth 
characteristic of revealing (Heidegger, 1977:12). This sense of bring-forth is an aspect of techne. Aristotle's distinguishing between techne and episteme clarified the manner in which knowledge is developed and acted upon, such that both constitute ways of knowing but that techne is distinguished by consisting of skills and activities specifically concerned with craft, arts, etc., in the manner of poiesis; that is, techne allows for the emerging of phenomena on its own terms. Put another way, Being reveals itself through its own myriad possibilities. This echoes the Orphean stance towards nature that Hadot describes, wherein man's place is within nature and is accepted as such; this is in contradistinction to the "setting upon" of modern technology that echoes the Prometheanism of Bacon.

Heidegger's characterizing of modern technology is a demanding that challenges nature to "standing-reserve" in a manner that both secures and regulates (Heidegger, 1977: 36). For example, the computer manufacturing industry relies on other industries ranging from applied physics to plastics, transportation for shipping products to market, publishing for printing instruction manuals, the oil industry to provide fuel for transportation vehicles to move the finished products, etc. The controlled functioning of many industries must all rely on each other and operate together in tandem. However, the regulation of these industries portrays an image of reality that has the appearance of competing industries and unpredictable economic forces.

The appearance of reality, however, belies a deeper ontological concern that Heidegger claims has become concealed amidst the ceaseless activity of ordering and securing. Ordering only lends itself to an appearance of control that pertains strictly to certain aspects of industrial society. The inverse is that man has no control over the real 
but rather only participates in the revealing and withdrawing of the real (Heidegger, 1977: 18). The activity of controlling and ordering industry, through technological means, has the effect of totalizing all conceivable phenomena as standing-reserve. This includes man but only in a qualified sense. Man having ordered himself according to a certain configuration is only one of many possibilities, a possibility that may reveal other possibilities towards which, presumably, man may comport himself. The issue of ordering gets to the essence of Heidegger's critique of technology, one that he describes as "enframing," in short, a "challenging claim which gathers man thither to order the selfrevealing as standing-reserve" (Heidegger, 1977: 19).

As discussed previously, the ordering characteristic of modern technology is rooted in modern metaphysics. This is why Heidegger insists that the essence of technology is not technological; the enframing tendency of modern technology follows from the metaphysical tendency to ascribe the world as present-to-hand qualities, an ascribing that is well suited to modern mathematics. This is why man is also set upon and challenged to reveal reality in a way that orders nature to standing-reserve. The axioms of modern physics construe nature as a "calculable coherence of forces," resulting in an ordering of nature that represents the expectations of physics.

Modern science establishes the positionality, that is, the framework and perspective, for conducting observations into nature. This framework in turn leads to the determination that specific technological apparatus' are needed for experimentation; these experiments constitute the method and proof for establish the certitude of hypotheses reinforcing the expectations of science. For this reason modern technology is a byproduct of modern science. The experimentation apparatus follows from the 
conceptual enframing of nature. It is not the case, for example, that advances in optics give way to a new understanding of light so much as a new way of thinking about light led to technological developments for determining the veracity of optical experiments; it is the modern framing of nature that allows for the flourishing of technology. This is what leads Heidegger to assert that the essence of modern technology emerges historically sooner than modern physics; in other words, the essence emerges and begins to hold sway before the explicit manifestation of scientific inquiry and technological systemization.

Applying technological principles of observation to nature results in nature represented as a "system of information," measurable down to its narrowest components. However, the systemization of nature does not map to a particular cause nor combination thereof, but rather, Heidegger asserts, causality itself becomes a component within the broadest conception of systemization as such (Heidegger, 1977: 23). The emergence of a universal, categorical system for the organization and elaboration of knowledge is the defining Baconian dream, a dream and goal that continues today in modern science. At the heart of this universalization is the discovery of a way of thinking which suggests the possibility of control. This possibility gives way to the refinement of procedure and systemization that provides verifiable and repeatable results, which, in turn provides positive feedback for further experimentation. Herein lies the danger that Heidegger identifies.

By establishing a way of thinking that provides certainty in the most efficient manner possible, man is constantly pushed towards a way of revealing that is only able to engage in a revealing that orders, in short, the revealing most recognized as scientific discovery 
(Heidegger, 1977: 25). Heidegger criticizes this approach for allowing only one way of truth to be revealed; rather than revealing itself it is instead challenged forth to represent nature according to predetermined calculations. This cordons off other ways for truth to reveal itself. Despite accurate calculations into natural phenomena, the danger remains that truth can withdraw, whereby man loses the experience of participating in the revealing and unconcealing of truth (Heidegger, 1977: 34). Systematic organization for man's perceived benefits is a vision dependent on the articulation of limits, in other words, the horizon of possibilities resulting from the ordaining of man's available options in turn proscribes the possibilities available to man according to the limits of vision.

An essential element of Heidegger's critique of technology resides in the meaning he ascribes to a particular way of observing the world. The essence of technology, enframing, is a way of challenging nature to yield up its energy for extraction and storage. What he describes as challenging follows from the Baconian dictum to order nature before oneself and wrest what can be gained. Enframing also refers to the making of decisions that frame the resulting historical context of late modernity and, arguably, post-modernity. The challenging sets in motion the eventual transformation of everything real into "standing reserve," that is, challenging each aspect of nature to yield up its own specific energies. Nature is henceforth divided up according to a predetermined "ground plan" that decontextualizes nature. Man too is challenged in this revealing, Heidegger argues, but not as simple standing reserve in the manner of the natural world. Despite the Cartesian claim of a new Archimedean Point, Heidegger argues that there is no privileged ontological vantage point from which to observe and control revealing (Heidegger, 1977: 24). This is not say that technology necessarily 
oppresses but rather that it is something modern man can't simply disengage from; it's a necessary aspect of the late modern epoch that characterizes phenomena as much as it determines it.

The key to understanding the modern era is in understanding the philosophical grounding that, as seen in Heidegger's argument, has more to do with the essence of technology than particular philosophical axioms. Understanding Heidegger's critique further requires an examination of the principle means of conduct in modern science, namely, research.

Heidegger explains that the essence of research is the first of three fundamental features of technology. Research consists in projecting a grid, or "ground plan," over nature, which allows for the opening up different fields of inquiry. With the grid in place hypotheses can be conjectured and established, leading to the creation of broad spheres of knowledge. Having defined the boundaries of a given field, new procedures are developed that further refine knowledge; doing so allows for an increasingly narrow focus between the lines of the grid.

The second feature is methodology. Projection of the ground plan, secured through the rigour of procedure, leads to the establishment of methodology (Heidegger, 1997: 120). Nature is torn open, according to Bacon's plan, and mapped out according to procedures. The measurement of life is probabilistic; without due consideration to random variables life is reduced to little more than inert spatiotemporal phenomena. Experiments are predicated on hypotheses, whose success hinges on the degree of accuracy of the ground plan into nature.

The third feature is that research is ongoing, so long as research continues then the 
projects in question will tend to grow in scope, drawing in additional industries. Institutions become necessary when science is conducted in the manner of research (Heidegger, 1997: 124). Thus the practice of science itself is modified to accommodate the pursuit of facts; in other words, a supposedly value-free pursuit of understanding of the world instead takes place entirely within the framework of constructed, purposeful technologies. This degree of coordination requires that individuals specialize their training for the industry to which they are employed and further requires that these specialists are able to communicate easily with one another.

In projecting a ground plan into the future and into the past both become objectified, resulting in a fixed view of the world. This representational view of the world is taken for truth, a representation first established by Descartes. Modernity has freed man from himself resulting in the rise of individualism and subjectivism, as well as having introduced the interplay of tension between subjectivism and objectivism. Heidegger indicates a further consequence in that following the Enlightenment the world had never in history agreed so widely on what exactly the world, in its entirety, really is (Heidegger, 1977: 134).

The collapse of religious tradition and its replacement with modern science and civic ideology constitutes a disappearance of what Heidegger calls the "suprasensory," which in turn is replaced by "the most uncanny of all guests," nihilism. The suprasensory refers ostensibly to the Christian tradition but Heidegger is quick to add that it can just as easily refer to the realm of ideas. With its evaporation the suprasensory has lost effective power, providing no mooring from which to align the direction of common everyday life as it once did. This is what led Nietzsche to state that we have reached the end of 
metaphysics. In The Gay Science, aphorism 125, Nietzsche famously describes the death of God, a loss that entails a "wiping away of the horizons," that is, of the limits of what can be known as well as of man's natural limits. Nietzsche conceives of Western history as the rise and development of nihilism and his own thought as a product of this development (Heidegger, 1977: 54).

Nihilism cannot be compared to any of the social or political fads that have come and gone over the last century. Rather, nihilism is a fundamental property of Western history according to Heidegger. He explains this by indicating that when a country enters the world stage it enjoins with the "realm of power" of the modern era, characterized by the advanced industrial societies of the West. In doing so the country forms a parallel relationship with the West, aligning its economy and industries with the West, which consequently lays the groundwork for the emergence of nihilism in that country.

In devaluing the highest values, the disappearance of God leaves the seat of authority open to ideologies and demagoguery; but this is only "incomplete nihilism," a state that is completed only after the notion of value itself, i.e., the seat of authority, is disintegrated will nihilism have consummated itself (Heidegger, 1977: 63). Cybernetics, as the apex of western philosophy, is precisely such a system, devoid entirely of values as an organization of an autonomous, self-regulating control and communication structure. 


\section{Chapter 4: Cybernetics and Political Disengagement}

Heidegger asserts that technology is metaphysics in the West and that cybernetics is the apex or culmination of a turn that began with Socrates (Heidegger, 1993: 434). For this assertion to become clear I will examine the origins and basic principles of cybernetic thought as articulated by its founder, Norbert Wiener, and explain how the philosophical tradition that Heidegger asserts has led to this articulation. This will lead to an examination of Heidegger's critique and what this means for the emergence of secondorder cybernetics, or "the cybernetics of cybernetics," whereby the principles of cybernetics are applied to itself. The consequences for philosophy will be examined considering Heidegger's philosophy and will be evaluated from that position.

It should be noted that adding the prefix "cyber-" to politics bears little relation to the application of cybernetic principles to political organization. When the term "cyberpolitics" is intended to imply increased political participation with computer communications this has no meaningful relationship to the original definitions established by Wiener, nor to the various developments of second-order cybernetics that emerged afterwards. Use of new social networking technologies, vote-tallying machines, online polls, increased use of online news media, etc., all constitute the most elementary and surface characteristics of technology applied to a particular realm of activity. In so far as particular technological applications may be used in politics they merely constitute the mechanical application of Cartesian ontology to political activity. In this sense they remain within the rubric of Heidegger's initial critique of technology. In so far as they assist in the ordering of political activity, foreordained towards particular ends, they 
contribute to the enframing characteristics of modernity and contribute to the deepening crisis that technological metaphysics bears for the West.

In the classic cybernetics of Wiener, the term "feedback" is used to articulate a mechanism for establishing automated control adjustments in devices ranging from thermostats to guidance systems to stock-market algorithms. The feedback mechanism is schematically independent from both the system in question and the observer (Wiener, 1961: 6). As hinted at in Plato's image of the politically unstable ship and fervor of its sailors, the general stability of a system is dependent on its most unstable point; developing a feedback mechanism allows for shifting over-reliance on the stability of a design towards points of weakness that the feedback mechanism can affect (Wiener, 1961: 108). Development of a proper "governor" allows for more efficient adaptation to circumstances, an adaptation that considers systemic capability within shifting contextual dynamics.

Political phenomena is the obvious point of inquiry of this essay as to whether or not cybernetic principles are applicable, and Wiener addresses the matter, but he is cautiously pessimistic that these principles can be applied to social or political institutions. Plato's city in speech is arguably the earliest iteration of the possibility of a perfected political order. The formalization of a method for distinguishing political efficacy provides a seductive possibility and cybernetics appears to offer just such a method. However, the actual manifestation of these notions may only be apparent in the militarization of arms development and the bureaucratization of political struggle (Wiener, 1961: 108). 
Cybernetics can be described as the result of the history of the refinement of this method, such that the project of experimentation describes its own developments by way of feedback. Feedback is the difference between what is intended as compared to its actuality, a difference that is fed back into the system as input for further systemic refinement. As such, even false leads, or "negative advancements," in experimentation are encouraged because they allow for determining what is not the case in so far as factuality can be further determined. In other words, by mapping the dead ends of scientific experimentation the pursuit of truth can in turn be further narrowed to its most precise inquiry.

Notions regarding the meaning of nature, what constitutes human nature, and man's relationship both to nature and to himself, undergo considerable change in the transition to modernity. Modern physics redefines nature according to observable properties whose content is characterized as information; that is, information arranged in a particular way characterizes knowledge only as a secondary interpretive effort applied by the observer. In this way information characterizes any organism capable of adapting and reproducing itself. In short, the characteristics of life are measurable according to quantifiable scales of information. Nature is thus defined according to observable organization represented by coherent information. The issue of how this is represented will be addressed again in Heidegger's critique of Cartesian ontology.

One method of determining systemic efficiency is to reduce variables to points of information quantitatively. Entropy is the inverse of organized information, in that it is a measure of disorganization within a system (Wiener, 1961: 11). Thus, a loss of information corresponds to a gain of entropy. To push the technical definition, 
phenomenological states that are not already in a state of complete dissolution will usually begin to be so eventually. Observable patterns in nature transform into pockets of organization in an otherwise chaotic universe of increasing entropy. Echoing Hobbes' articulation of "matter in motion," nature represents an array of phenomena that are observably neutral regarding the measurable probability of their dissolution. In this articulation nature tends to destroy order and meaningfulness (Wiener, 1954: 17), which inverts the classical Greek understanding of nature as part of a rationally ordained cosmos. The effectiveness of cybernetics rests precisely in the degree of control its methods are capable of exerting over entropy, i.e., nature (Wiener, 1954: 26).

Restating the scientific interpretation of nature, i.e., as interpreted, allows for the emergence of phenomena that are purely quantitative in representation. For example, temperature is an observation of a purely representable quantitative scale abstracted and codified from the original experience of heat and cold. Quantifying phenomena allows for the distancing of human consideration regarding the issue at hand. Thus Wiener asserts that technology remains neutral in itself, though allows its use for good and evil (Wiener, 1961: 27).

There is an obvious gain in speed and efficiency regarding the automation of certain human labours, what historically was the target of Marx's chief diatribes concerning life in the industrial era. Replacing otherwise average human performance with more efficient machines may not necessarily improve political society. By framing the output of human activity in terms of economic-value Wiener asserts man must choose values appropriate to a technological society, however, his articulation remains within the rubric of valuation that already characterizes industrial society defined by economics. 
Cybernetics picks up the modern notion of explicit control of nature and seeks to establish a method that will allow for incremental systemic improvements. Wiener recognizes that blind faith in the applicability of refinement to political order would likely yield terrible results. The initial difficulty associated with the application of cybernetics to social phenomena parallels one of the tenets of the modern scientific method, namely, that the observer is separate from the subject-experiment to mitigate the possibility of corrupting results inadvertently through observational contact. Thus, cybernetics is limited in application because social scientists cannot extricate themselves from the subject of study; in other words, the social scientist is as much a part of the experiment. At best, only small-scale test and observation is possible but there yet remains the difficulty of mitigating influence by the observer (Wiener, 1961:24).

Nevertheless, the promise of effectiveness obtained through cybernetic methods remains seductive. Because of the scientific assumption that all phenomena can be reduced to quantitative frameworks, there remains the logical possibility that statistical measurement of society will be amenable to cybernetics and that policy application may follow. Wiener identifies that the chief difficulty is already illuminated by the very topic of cybernetic inquiry, that is, the study of control and communications. By this he identifies three impediments to the adoption of cybernetic principles in society: the elimination of less profitable means of communication in favour of more profitable means; the means of communication are controlled by wealthy interests; control of communications is the chief avenue towards profit and power, which therefore will attract those individuals most interested in profit and power (Wiener, 1961: 161).

Wiener further suggests that the issues of politics, avarice, and greed are perennial 
and that those individuals most interested in solving them are those also most likely to believe that cybernetics will have a significant effect on society. Cybernetics can demonstrate effectiveness most clearly in cases where the observer is separated from the subject of observations; however, isolation is very difficult in social engineering and so least likely to provide effective feedback in the application of cybernetics.

Wiener notes that the same impulse, which leads to, the development of modern mathematical logic has also contributed to the mechanization of thought (Wiener, 1961: 12). If information is characterized as ordered meaning, imposed by rational observation, then it follows that nature is the antithesis of meaning. Thus, meaningful action in the world is possible only when we receive rational signals fed back to us from our own actions. Therefore increased control is the logical of the rational and ordered representation of the world, not only for security in political order but also in the fabrication of meaning.

Modern physics is not concerned with the totality of meaning within the universe so much as narrowing the scope of meaningful inquiry in the universe (Wiener, 1954: 21); thus, "possible worlds" becomes a meaningful extension of the actual world because purely conjectural representation is just as meaningful because of information returned to an observer engaged in rational speculation.

Wiener doesn't agree that an overt Leviathan-like control mechanism will likely be erected; rather, the real danger is in allowing power-hungry individuals to apply narrow machine-like techniques to political control (Wiener, 1961: 108). Arguably this has already met and failed in that grand social experiment called the U.S.S.R. However, the application of technological thinking to perennial issues of politics remains a danger that 
is not at all obvious given advances both in technology proper and the likes of cybernetic theory. It is the purpose of this essay to explore this danger, particularly the case of second-order cybernetics applied to politics, but before that it was necessary to examine Heidegger's critique of cybernetics and the foundation that this critique rests on. The danger remains in the promise of a perfected political order achievable through proper technique, a promise that is permanently feasible due to the philosophical tradition's insistence that truth is always ascertainable from the false. Heidegger's critique of the tradition indicates how this certainty may be called into doubt.

Examination of the limitations inherent to classical cybernetics led to a reconceptualization of the central contributions to the field. There are several basic tenets to second-order cybernetics, which I will outline below, whose main contributors will be mentioned and briefly compared. In doing so I will establish a connection between these changes and how they are relevant to Heidegger's broader critique of technology and his specific insights concerning cybernetics. The principle trajectory of this analysis will examine the metaphysical consequences considering second-order cybernetics for Heideggerian thought, with brief mention of how this relates to the fields of constructivism and post-modern critical theory.

The relevance to Heidegger does not rest in a simple oppositional critique of method or metaphysical assumptions, nor in adherence to this or that philosophical tradition. Despite Heidegger's critique concerning the limits of technological thought, there are interesting and disturbing parallels between his criticisms and some conceptual articulations by contributors to second-order cybernetics. These parallels range from a 
rejection of overt technological control mechanisms applied to society, to redefinitions of what constitutes living entities, to the possibility of coherent communication between disparate systems. The connotations of constructivism and late post-modern studies in communications will become clear following an examination of second-order cybernetics.

The work of Von Foerster contributed most towards the formalization of secondorder cybernetics from its initial proving ground with Wiener. The essential ideas he contributed include the recursive characteristic of circularity applied to system feedback, which I've discussed at length already. One of them is inclusion of the observer when considering systemic effects; this has lead to the use of first-person statements when documenting experiments in cybernetic projects. Furthermore, Von Foerster and his colleagues established grounding in the sciences for what essentially is the post-modern expression of the construction of reality; as with artificial systems, reality is something constructed and shared by its members. These premises formed the groundwork for more specific theoretical clarifications by other scientists that, for the purpose of this thesis, will be restricted to the strongest contributors of cybernetic theory concerned with applications to social institutions.

The central concepts of second-order cybernetics, summarized by Glanville, are the following. What distinguishes second-order cybernetics is the application of the subject to its own subject matter. Inclusion of the observer, and recognition of the observer's actions upon the system, constitutes an ethical dimension. System stability is measured according to its ability to sustain itself irrespective of external references; this is closely

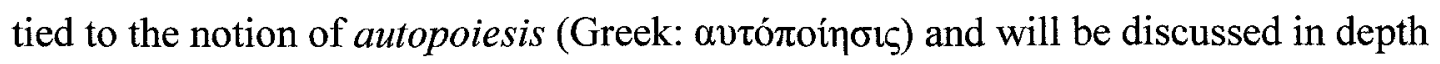


below. This stability is further distinguished by shifting the weight of importance from an external feedback mechanism to its own systemic design. This leads to issues of autonomy and identity inherent to self-reference. Autonomy implies exteriority and recognition of other systems that leads to the issue of "conversational communication"; when the observer is factored into the system reference, autonomous yet still involved, then referents and signs are subjective according to the observer. Incremental improvement is the goal rather than an idealized perfect system; second-order cybernetics is concerned with factoring in particular observers and circumstances, according to autonomous individuation, which precludes the need for measurement against an unattainable idealization. Finally, circularity of the system is an essential component that distinguishes second-order cybernetics from its theoretical precursor, providing the boundaries for autonomy and the framework for autopoietic maintenance (Glannville, 2000: 10).

The aspect of second-order cybernetics that most concerns this thesis is autopoiesis and how this is connected to Heidegger's critique of technology in particular, but also his critique of modern metaphysics. Autopoiesis originates from ancient Greek as "selfmaking" and is a term applied in cybernetics to systems capable of automatically adjusting their configuration to account for changes in the environment, with the specific aim of maintaining their designated configuration, for example, a bionic heart that is able to continuously perform its task despite ongoing fluctuations of the host body. Maturana is the principle contributor of the principle of autopoiesis to second-order cybernetics; his definition is quoted in full:

"A machine organized as a network of processes of production of components that produce the components which: (i) through their interactions and 
transformations continuously regenerate and realize the network of processes that produced them; and (ii) constitute it (the machine) as a concrete unity in the space in which they (the components) exist by specifying the topological domain of its realization as such a network." (Maturana, 1980: 79)

From this definition autonomy is present in living organizations in so far as they exhibit unity, therefore, organization and autonomy are coterminous. Maturana identifies a common pattern of organization in all living systems, irrespective of particular components, which leads him to declare everything that is alive a machine; so long as processes are autonomous, individuated, and can operate in unity independent of input or output, then autopoietic organization is present and therefore is classifiable as a living machine. This conceptual framework presents a method for describing how, e.g., bionic prosthetics can interact with the human brain by providing a means for the limb to carry out the details of motion that conscious attention by the person would not be able to perform beyond crude, oscillating articulations.

The question of autopoiesis and society should now be considered in the narrow context of second-order cybernetics, as well as within the broader questioning of technology expressed by Heidegger (Heidegger, 1993: 434). In the early Macy Conferences on Cybernetics, the anthropologists present expressed an early articulation of the possibility of social improvement that applied cybernetics might offer. The desire to address social issues through novel reconfiguration of social factors is at least as old as the Republic; the issue of depth and scale of reform is the stage, or perhaps slaughter bench, upon which the history of politics plays out.

Niklas Luhmann applied second-order cybernetics to the possibility of developing a new framework for analyzing society in terms of "social systems." It must be emphasized that this very much describes society as a system and not merely society as 
such. Luhmann's extension of the definition of autopoiesis incorporates a distinct connection to the relevance of communication between components within a system, particularly in the context of structural reproduction that will be examined below.

The underlying implication of self-making remains in Luhmann's writing but the emphasis is on the relationship between the components within the system rather than emphasizing the structure per se. By shifting emphasis towards components then a parallel argument can be made for discussing individuals and institutions. The interactions among individuals and institutions within society constitute the regenerative activities that describe an autopoietic system; the communication system within the broader "social system" allows for the maintenance of structures that reproduce themselves, which in turn allows for society to continuously emerge around it (Luhmann, 1995: 162). However, mere reproduction is not enough; society doesn't simply remake itself and expire, to be replaced by offspring phylogenically. Rather, the system remakes itself and in doing so simultaneously replaces and provides the circumstances for future continuity. Luhmann asserts this by establishing a correlation between components based on their communicative abilities. Communication takes place between all components in the coming-to-be and passing-away of the simultaneous remaking of society; this communication results in the internal differentiation of components, which is the context that allows for reproducing the possibility of reproduction (Luhmann, 1995: 189).

In such a formulation, society constitutes a series of nested subsystems, each engaged in interrelated communication. Though there is differentiation for each component, the boundaries separating each component are not necessarily the boundary for itself; that is, what constitutes a boundary for one system may be a component in 
another. The unity of components remains, i.e., society as such remains, despite a reformulation of traditional definitions. Thus, both society and nature are differentiated yet both are constitutive of systems built up from nested subsystems. This leads to the emergence of reciprocity, as each component within a system is able to engage with others, engendering differentiation; so long as circularity of communication emerges then social systems emerge as self-referential systems.

Maturana is attempting to establish a new definition of life in terms of information systems; however, this approach remains grounded in the seeming permanence of Cartesian extensia. By accounting for the ontological shortcomings identified by Heidegger the framework for identifying living systems remains within traditional epistemological parameters and carries the ontological baggage previously identified with it.

Another weakness with Maturana's use of autonomy is the failure to address the ontological significance of man over and above the artificial system, be it a bionic prosthetic or a stock market algorithm. His account of life, recast as information systems, doesn't quite "level down" man to the equivalence of an automaton, nor raise the significance of the artificial to the same ontic status as man. By this rubric man is capable of reproducing the internal conditions necessary for adaptability but this only accounts for physiology and does nothing to account for the diverse array of ontologies indicated by Heidegger.

There are further ontological difficulties with Maturana's approach. By predicating the definition on autonomy, Cartesian dualism is deepened because the "processes of production" indicated above are autonomous in their participation within the broader 
system. While the technical manifestations possible in an artificial system designed around Maturana's ideas may yield success, the definitions provided by him are too broad in scope to properly account for ontological considerations, or are too narrowly Cartesian to allow for broad diversity.

However, the unity promised by cybernetic application to society is not characterized by the traditional grounding man has towards his ownmost fundamental self-recognition, be it the Greek polis, the Roman societas, or the eternal city of the Christians. The fundamentum does not recapitulate in the technological society. Rather, there is an elaboration of the Archimedian Point that is infinitely situated for each individual. A parallel can be made in the transition from Greek aletheia to Latin veritas; the inherent ambiguity of the former allowed for a free and rich range of expression, but the transition to Latin narrowed the meaning of truth to what can be reckoned. This narrowing occurs in the definition of thinking as well, in the linguistic transition from Greek logos to Latin ratio. Despite Luhmann's attempt to establish a new ontological approach to the study of society he remains locked within the Cartesian differential calculation of ratio.

As first articulated by Bacon, the task of modern science is the identification, classification, and cataloguing of nature according to rational principles of organization. Redefining nature as a framework of interconnected subsystems, overlaid upon a neutral spatio-temporal matrix, results in important metaphysical consequences. Nature, defined as an "environment" establishes an overall framework that sets a way of ordering man's relationship to himself as well as to the context in which he operates. Operationalizing 
man's activities in this context results in a situational emplacement within a framework constructed as object and into which man interjects himself as subject.

Nature, human nature or otherwise, construed as a system is placed before the ordering of man, an ordering grounded on mastery of nature. The Baconian call to organization, in conjunction with Cartesian subject-certainty, establishes the metaphysical boundaries of modern philosophical inquiry. These boundaries are set by man according to his own needs, upon a ground of his own fashioning. If so needed, the framework can be adjusted to match the needs and expectations of the project of mastery; therefore the re-grounding of man according to predetermined expectations even allows for rejection of "human nature" altogether. In remaking nature, man is remade according to the image set before him. Bacon's inversion of the highest aims of classical philosophy, whose skyward gaze sought beyond the ineffable, has resulted instead in the enshrinement of the lowest common denominator.

Nature construed as an environmental system replaces nature as such, in so far as it can be experienced in a more primordial fashion independent of the expectations of modern metaphysics. The representational system of a constructed framework, within which redefined human nature is interjected, erects an arena of thinking which further distances the possibility of an experience with phenomena of the sort that Heidegger describes. Such an arena constitutes a framework within which man establishes philosophical inquiry, predicated on Cartesian suppositions as ordained by the Baconian project, but when combined with cybernetic principles of autopoiesis and self-regulation, results in the engendering of automatic and regulated stability.

Second-order cybernetics is defined in part by the presence of mechanisms that 
respond to observer interaction, mechanisms whose character is determined during construction of the system. Cybernetic systems are engineered according to the purpose whose means they are intended to carry out. Such a system reintroduces the cause that Heidegger suggests has almost been forgotten, namely, the teleological cause of phenomena. Refashioning man and nature according to predetermined needs and desires result in the creation of a system built to satisfy purposes determined in advance. Hobbes' formulation of man as the creature that makes himself now also creates new purposes in a system of his own creation, whose purposes in turn emerge from internal systemic needs to direct man.

Cybernetic systems are demonstratively coherent according to the internal logic of their design. Situational adaptively manifests according to the degree of its responsiveness; in other words, a system demonstrates second-order cybernetic characteristics because it will respond to our inquiries, a response that is not necessarily predictable but rather variable and thus indicative of circumstantial variance. Because responses will vary according to circumstances, yet remain coherent according to systemic internal logic, there is a degree of enclosure that indicates a circular cohesiveness; that is, the system is identifiable by its constitution, a boundary that describes a closed system responsive to inquiries made both of and within it. Thus, the occurrence of unanticipated responses indicates an engineering failure of accommodation regarding the breadth of inquiries possible, rather than a sign indicating the system design is fundamentally deficient. This marks the transformation of efficiency into a moral value and the transformation of moral values into system parameters for a technological society. 
Nietzsche describes the advent of nihilism beginning not with the positing of values as such but in establishing the conditions that allow for value positing. Such valuing within a system predicated on second-order cybernetics will arrive at suppositions derived from observations of the signs produced by the feedback mechanism of the system. Cybernetic systems are typically engineered to accommodate varied input to provide feedback communicated by the system; as such, system responses will necessarily be indicative and limited to the system itself. In other words, circularity is maintained by the internal logic of a system capable of responding to valuations made within the system. Philosophical inquiries made into human nature, formulated according to the demands of a system predetermined to provide results determined in advance, will result in automatic affirmation of every value posited within a cybernetically-organized society, be it a corporation or a state.

Creation of a responsive and dynamic system capable of sustaining any valuation posited within it creates a condition of intractability. This occurs because a cybernetic system constituting the metaphysical framework immerses questioning in such a way that all inquiries posed to the system receive responses whose content is already built into the system itself.

This circumstance allows for entry into, but not withdrawal from, the system. In other words, immersion into a system whose "environment" is constructed according to systemic expectations mitigates the possibility of stepping back out. The possibility of reestablishing the distinction between man and his created system dissolves because immersion deepens the differentiation between phenomena; the tendency of systemization is towards increased differentiation through application of discrete 
properties to increasingly indistinguishable phenomena.

These considerations applied to the broader issue of political order or social movements becomes clear. Hyper-organization of the study of social phenomena tends towards reification of categories; designating statistical measurement feedback results in a deepening of the immersion into Cartesian representation of the world, or as Heidegger describes, a "world picture." References limited to abstractions written into the system of measurement is in turn relied on to provide measurements. The circular cohesiveness of such an arrangement lacks a critical position that doesn't already emerge from, or is based upon, formal Cartesian ontology.

The limits established by modern metaphysics are not obvious but with the application of cybernetics to politics what emerges is a curious set of consequences. In creating a system of independent, objective standards fashioned according to the axioms of modern science, the organization of political order then falls under the command of modern science. Purely subjective participation in the public realm is drained of the dynamism observed in former eras, replaced by the neutrality of technological arrangement.

This arrangement doesn't allow for a metaphysical alternative to the most logical organization possible. This results in a situation that feeds on itself, according to the predetermined organization of the system. Relying on the system for feedback in the measurement and observation of political activity automatically reasserts its own values, based on the possible range of values predetermined in the construction of the system. The possibility of withdrawing becomes difficult, if not strictly impossible, because the system is all-immersive; the means of technological organization are derived from a 
metaphysically technological framework.

When the framework is built with a mechanism that allows for automatic adjustment and systemic reorientation, based on dynamic circumstances within the system, then the system will adapt according to the logic engineered into it, in other words, it will "run itself." 


\section{Conclusion}

Classic cybernetics has provided a conceptual framework for elaborating the designs of systems that automate themselves according to input from the environment. This idea is hinted at in Plato's image of the ship, from which the "governor's science" emerged. This conceptual orientation is a clear step further away from reliance on the good graces of the divine or of fortune. In it's most protean form what emerges is an epistemology that looks to the observable world as its reference from which decisions might be made and upon which action is undertaken. From this early start a trajectory can be followed that eventually results in automated inventions that are able to process information from the environment and make decisions in accordance to what is expected of them, independent of human involvement.

Attempts to prevent over-oscillations from occurring in prosthetics development was achieved through this method; the benefits for medical advancement and alleviation of suffering are obvious and few would contest whether, subjected to such circumstances, it were worthwhile to accept continued development. And yet, this is precisely the argument that Nietzsche criticizes in his excoriation of the modern West; unlimited mastery over nature and wiping away the horizons of man's limits has resulted in unlimited technological innovation.

There is a fine distinction between innovations that give rise to advances that allow for a restorative quality, mitigating the worst of life's vicissitudes; the same advances may also allow for transgressions of natural limits that the ancients felt worth respecting. The innovations that provide prosthetics emerged from the same epistemological framework as nuclear missile technology; the same ontological preconditions lead to 
inventions that ostensibly free us from nature's shackles but, like wishes the Genie grants, just as often result in warped unforeseen consequences.

It is a facile truism to make such comparisons; nevertheless, material innovations remain the most obvious results. The self-engendering organization that cybernetic principles provide, in the domain of political order, may prove insidious because the consequences are not at all obvious. Attempts at developing measurement tools to determine the effects will be drawn from the same epistemological pool that created the modern industrial system. In other words, they will be built from the axioms of modern physics that lie at the heart of modernity.

Attempts at measuring the effects of a political order arranged according to the most efficacious structure will return results that favour arrangement towards increased organization. The autopoietic quality of the feedback system will provide the regulatory means for self-maintenance but this will result in furthering the immersiveness of the system.

The question of whether cybernetics can be chosen or not is a moot point for Heidegger. Cybernetics is metaphysics in the West; it constitutes the apex of metaphysics and the highest order of technological thought. Ellul asserts that with the discovery of more efficacious techniques, the older techniques can no longer be employed; efficiency makes demands on circumstances that can't be avoided except in the most banal cases. The question of whether to use a more efficient technique in the performance of brain surgery is no question at all; but for a walk to work the most efficient approach is not necessarily the best. Thus, only the most banal circumstances remain open. 
Such a formulation grants too much agency to technique. It alleviates individual agency, that is, the responsibility and necessity of choice in the determination of how to conduct one's actions, irrespective of circumstance. That Ellul suggests that one has "no choice" but to accept the most efficient is indicative of the overbearing influence of Cartesian ontology on the experience of life in the industrial West (Ellul, 1964: 80). Heidegger's assertion that cybernetics is the apex of metaphysics is not a championing of metaphysics, nor a celebration of the advancement of technology in Western civilization; Western thought is characterized by technological thought in the modern era. The next step in the logical progression of technology is a way of thinking that pounces upon whatever is most efficacious in every circumstance irrespective of need.

Technological metaphysics characterized by self-making, automatic adjusting, logical enclosure, and systemic independence are all logical steps in technological advancement. Heidegger disagrees with the notion that only the most efficient is the only option. However, he offers no alternative solution to what is becoming a planetary benchmark. What he does hint at is the possibility that only pushing forward through the inner dynamic of Western technological metaphysics will allow man to experience ontological possibilities that are currently inaccessible. The subtext is apocalyptic and may well point to one of Nietzsche's darker predictions for the West. 


\section{Bibliography}

Aristotle., and Carnes Lord. The Politics. Chicago : University of Chicago Press, c1984. Print.

Aristotle. Nicomachean Ethics. Tran. Joe Sachs. Newburyport: Focus Publishing, 2002. Print.

Arendt, Hanna. The Life of the Mind. San Diego: Harcourt Brace, 1977. Print.

Bacon, Francis, and Rose-Mary Sargent. Selected Philosophical Works. Indianapolis, IN: Hackett Pub., c1999. Print.

Descartes, Renâe. Philosophical Essays: Discourse on Method; Meditations; Rules for the Direction of the Mind. Tran. Lafleur. Indianapolis,: Bobbs-Merrill., 1964. Print.

Ellul, Jacques. The Technological Society. Tran. John Wilkinson. New York: Knopf, 1964. Print.

Glanville, Ranulph. "A (Cybernetic) Musing: The State of Cybernetics." Cybernetics \& Human Knowing, Vol.7, no.2-3 (2000): 151-159. Print.

Grant, George. Time as History. Toronto: Canadian Broadcasting Corp, 1969. Print.

Heidegger, Martin, and David Farrell Krell. Basic Writings : From being and Time (1927) to the Task of Thinking (1964). Rev. and expanded ed. San Francisco: HarperSanFrancisco, c1993. Print.

Heidegger, Martin, and William Lovitt. The Question Concerning Technology, and Other Essays. 1st ed. - ed. New York ; London: Harper and Row, 1977. Print. 
Heidegger, Martin. Being and Time. Tran. John Macquarrie and Edward Robinson. New York,: Harper, 1962. Print.

Heidegger, Martin. Introduction to Metaphysics. Tran. Gregory Fried and Richard Polt. New Haven : Yale University Press, c2000. Print.

Heidegger, Martin, and David Farrell Krell. Nietzsche vol 4. 1st ed. ed. San Francisco: Harper \& Row, 1979-1987. Print.

Hobbes, Thomas, and E. M. Curley. Leviathan : With Selected Variants from the Latin Edition of 1668. Indianapolis: Hackett Pub. Co., c1994. Print.

Maturana, Humberto R., and Francisco J. Varela. Autopoiesis and Cognition : The Realization of the Living. Dordrecht, Holland; Boston: D. Reidel Pub. Co., 1980. Print.

Nietzsche, Friedrich Wilhelm, and Walter Kaufmann. Beyond Good and Evil; Prelude to a Philosophy of the Future. New York: Vintage Books, 1966. Print.

Nietzsche, Friedrich Wilhelm, and Walter Kaufmann. The Gay Science; with a Prelude in Rhymes and an Appendix of Songs. New York: Random House, 1974. Print.

Plato, and Allan Bloom. The Republic of Plato. 2nd ed. New York: Basic Books, 1991. Print.

Roochnik, David. Of Art and Wisdom : Plato's Understanding of Techne. University Park: Pennsylvania State University Press, 1996. Print.

Sachs, Joe, and Aristotle. Aristotle's Physics : A Guided Study. New Brunswick: Rutgers University Press, 1995. Print. 
Voegelin, Eric. Order and History. Baton Rouge: Louisiana State University Press, 19561987. Print.

Voegelin, Eric. Science, Politics, and Gnosticism. Wilmington: ISI Books, 2007. Print.

Von Foerster, Heinz,. Understanding Understanding Essays on Cybernetics and Cognition. New York : Springer, c2003. Print.

Wiener, Norbert. Cybernetics; Or, Control and Communication in the Animal and the Machine. 2d ed. New York: M.I.T. Press, 1961. Print.

Wiener, Norbert. The Human use of Human Beings ; Cybernetics and Society. New York, Avon Books: 1967. Print.

Zinman, M. Richard, Arthur M. Melzer, and J. Weinberger. Technology in the Western Political Tradition. Ithaca: Cornell University Press, 1993. Print. 